University of Rhode Island

DigitalCommons@URI

Open Access Master's Theses

1994

\title{
STUDY OF MICROENCAPSULATED PRODUCTS WITH RESPECT TO THEIR ABILITY TO PREVENT INCOMPATIBILITIES
}

Harish K. Pimplaskar

University of Rhode Island

Follow this and additional works at: https://digitalcommons.uri.edu/theses

\section{Recommended Citation}

Pimplaskar, Harish K., "STUDY OF MICROENCAPSULATED PRODUCTS WITH RESPECT TO THEIR ABILITY TO PREVENT INCOMPATIBILITIES" (1994). Open Access Master's Theses. Paper 277.

https://digitalcommons.uri.edu/theses/277

This Thesis is brought to you for free and open access by DigitalCommons@URI. It has been accepted for inclusion in Open Access Master's Theses by an authorized administrator of DigitalCommons@URI. For more information, please contact digitalcommons-group@uri.edu. 
STUDY OF MICROENCAPSULATED PRODUCTS WITH RESPECT -TO THEIR ABILITY TO PREVENT INCOMPATIBILITIES

BY

HARISH K. PIMPLASKAR

A THESIS SUBMITTED IN PARTIAL FULFILLMENT OF THE REQUIREMENTS FOR THE DEGREE OF

MASTER OF SCIENCE

IN

PHARMACEUTICS

UNIVERSITY OF RHODE ISLAND 


\title{
MASTER OF SCIENCE THESIS
}

\author{
OF
}

HARISH K. PIMPLASKAR

APPROVED

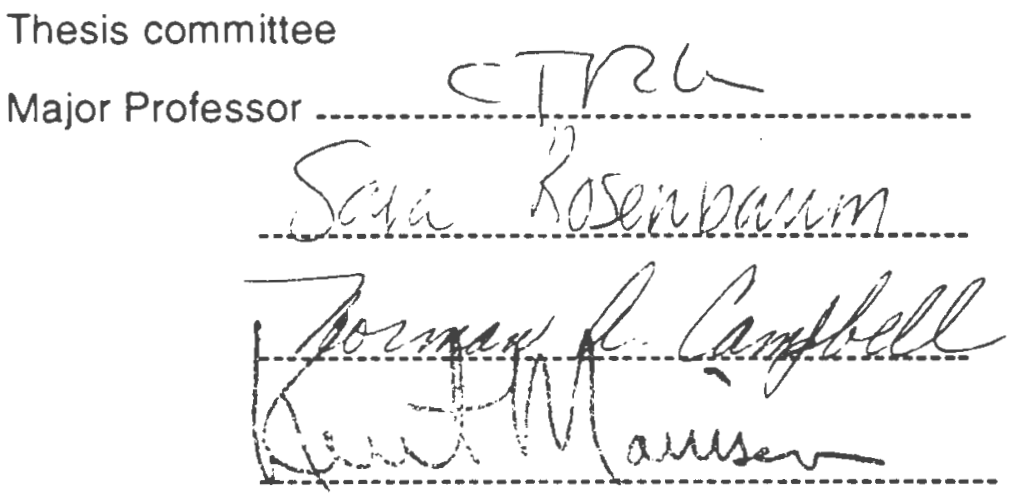

DEAN OF THE GRADUATE SCHOOL

UNIVERSITY OF RHODE ISLAND

1994. 


\section{ABSTRACT}

The interaction between drugs and excipients or between drugs and other drugs in the same dosage form have potential to modify safety and efficacy. In some cases the interaction can be of such a degree as to preclude the use of some excipients or to dramatically reduce the shelf life of the products. Thus there is clearly a need for techniques which can reduce or eliminate such interactions.

Sometimes the irrational combination of two drugs or drug and excipient cause a decrease in the stability, bioavailability and efficacy of the dosage form 1. Microencapsulation can be considered as a tool to enhance the drug stability 2 . It has generally been observed that microencapsulated products show a substantial reduction or elimination of the adverse effects of incompatibilities, although quantitative data on the extent of stabilization is not readily available in the published literarture.

The primary objective of this study was to determine the drug interactions and incompatibilities between drugs and excipients which are widely used in pharmaceutical manufacturing and have some characteristic compatibility problems. I did these studies on powder mixes and compressed tablets owing to the fact that majority of the dosage forms are formulated in the solid state 3. The study included three drugs namely aspirin, acetaminophen and pseudoephedrine ( hydrochloride salt ).

The interaction between aspirin and dibasic calcium phosphate ( Emcompress ) was studied in detail. Non - microencapsulated aspirin showed significant degradation by hydrolysis in presence of Emcompress at room temperature as well as elevated temperature. Microencapsulated aspirin 
showed a marked decrease in the degradation under same conditions. The stabilizing effect of the microencapsulation was both statistically significant and substantial.

The interaction between acetaminophen ( APAP) and diphenhydramine hydrochloride and phenylephrine hydrochloride was monitored for the presence of degradation products. These agents showed incompatibility with acetaminophen when used in the proportion which was the same as that of an over the counter product. The manifestation of incompatibility was melting point depression by eutectic formation. The eutectic formation was prevented when microencapsulated acetaminophen was used.

Non - microencapsulated acetaminophen showed significant adsorption over antacids like aluminum hydroxide, magnesium trisilicate and calcium carbonate. Microencapsulated acetaminophen demonstrated appreciable decrease in the rate and extent of adsorption under similar conditions.

I had planned the compatibility studies of pseudoephedrine $\mathrm{HCl}$ with hydrous lactose and with sodium metabisulphite. The literature showed evidence of some degradation products. However initial tests showed no significant compatibility problems and hence no further experimentation was performed on these substances. However the interaction of pseudoephedrine and acetaminophen and pseudoephedrine and aspirin was monitored for the degradation products.

A battery of in process quality control tests such as appearance, weight variation, content uniformity, surface characters, flowability, friability, and moisture content were performed on all three formulations. All results were evaluated using conventional statistical techniques using factorial design and 
the differences between microencapsulated and non microencapsulated products were determined at $95 \%$ confidence intervals. Both the groups were compared using tests such as ANOVA ( Analysis of Variance), Student's t test ( two tailed), and simple regraession analysis with the help of a software on a microcomputer. 


\section{ACKNOWLEDGMENTS}

I want to express my profound appreciation for not only the guidance of my major professor, Dr. Christopher T. Rhodes but also his support of all my endeavors. Without the help of Dr. Rhodes, my progress over the last two and a half years would have been stunted. I found an excellent teacher and great advisor in him. I would like to thank Dr. Sam Ghanta, R \& D director of Eurand America for his guidance and financial support without which this work would not have been completed. I also would like to thank Dr. Norman Campbell and Dr. Sara Rosenbaum for serving on my M. S. thesis Committee.

I am grateful to Dr. Thomas E. Needham, chairman of the pharmaceutics department for making me available the laboratory facilities in the college of pharmacy. I am also grateful to all the faculty and the staff in the department of pharmaceutics for their help and encouragement on various occasions.

All my colleagues and friends in the department of pharmaceutics and the URI community deserve a special note of thanks. I would like to thank Dnyanesh, Dr. Kottke, Carl, George, Polireddy, Suresh, Alpana, Lin, \& Dr. Anita Nanda for their continued support and encouragement throughout my ' graduate studies.

My family members and friends back home in India were the constant source of understanding, love and support in my career. They significantly helped mold my career and outlook towards life. I greatly appreciate their utmost patience and trust in me.

Finally I would like to dedicate this work to my dearest mother who means everything in life to me. Whatever little success I have achieved in my life and career is because of her. I really feel proud to be the son of such a wonderful and loving mother. 


\section{PREFACE}

This thesis is prepared according to the manuscript format which is permitted under section 11 - 3 of the Graduate Manual of the University of Rhode Island. The Manuscript will be submitted for publication in Drug Development \& Industrial Pharmacy.

Some of the experimental data in this thesis was presented as a poster in eighth annual meeting and exposition of the American Association of Pharmaceutical Scientists. ( AAPS ) held at Orlando, Florida in November 1993. 


\section{TABLE OF CONTENTS}

PAGE

ABSTRACT

ii

ACKNOWLEDGMENTS

v

PREFACE

vi

TABLE OF CONTENTS

vii

LIST OF TABLES

ix

LIST OF FIGURES

xii

ABSTRACT

2

INTRODUCTION

4

MATERIALS AND METHODS

6

RESULTS

11

DISCUSSION

45

CONCLUSIONS

48 
PAGE

REFERENCES

50

APPENDIX A

52

APPENBDIX B

59

APPENDIX C

63

APPENDIX D

80

BIBLIOGRAPHY

87 


\section{LIST OF TABLES}

MANUSCRIPT

PAGE

TABLE 1 : Percentage degradation of aspirin in presence of emcompress in powder mixes 18

TABLE 2 : Percentage degradation of aspirin in presence of emcompress in direct compression tablets.

TABLE 3 Interaction of acetaminophen with various antacids in the powder mixes.

TABLE 4 : Student's $t$ test for microencapsulated and non microencapsulated aspirin in presence of Emcompress.

TABLE 5 : ANOVA of microencapsulated and unencapsulated acetaminophen in presence of aluminum hydroxide-.--.-.-.-.-----30

TABLE 6 : ANOVA of microencapsulated and unencapsulated acetaminophen in presence of calcium carbonate

TABLE 7 : ANOVA of microencapsulated and unencapsulated acetaminophen in presence magnesium trisilicate. 32 
TABLE 1 : Dissolution data of acetaminophen and aluminum hydroxide tablets

TABLE 2 : Dissolution data of acetaminophen and calcium carbonate tablets. 65

TABLE 3 : Dissolution data of acetaminophen and magnesium trisilicate tablets.

TABLE 4 : Molar absorptivities of aspirin and salicylic acid at $258 \mathrm{~nm}$. and $302 \mathrm{~nm}$. respectively.

TABLE 5 : UV analysis of samples containing non-microencapsulated aspirin as an average of three measurements.( powder mix) $-70$

TABLE 6 : UV analysis of samples containing microencapsulated aspirinas an average of three measurements. (Powder mix)

TABLE 7 : UV analysis of samples containing non microencapsulated aspirin as an average of three measurements.

TABLET 8 : UV analysis of samples containing microencapsulated aspirin as an average of three measurements. $-73$

TABLE 9 : Calibration curve data of non - nicroencapsulated aspirin.---------74

TABLE 10 : Calibration curve data of microencapsulated aspirin.-.---.-----.----75

TABLE 11 : Calibration curve data of non - nicroencapsulated acetaminophen.

TABLE 12 : calibration curve data of microencapsulated acetaminophen.---77 
TABLE 13 : Calibration curve data of non - microencapsulated pseudoephedrine hydrochloride.

TABLE 14 : Calibration curve data of microencapsulated pseudoephedrine hydrochloride. $-79$

TABLE 15 : UV absorbance data of pseudoephedrien hydrochloride and acetaminophen mix at $45 \mathrm{C}$ and $60 \%$ R. H

TABLE 16 : UV absorbance data of pseudoephedrine hydrochloride and acetaminophen mix at room temperature $-84$

TABLE 17 : UV absorbance data of pseudoephedrine hydrochloride and acetaminophen tablets at $45 \mathrm{C}$ and $60 \% \mathrm{R} . \mathrm{H}$.

TABLE 18 : UV absorbance data of pseudoephedrine hydrochloride and acetaminophen in tablets at room temperature. $-86$ 


\section{LIST OF FIGURES}

MANUSCRIPT

PAGE

FIGURE 1 : Scanning electron micrograph of aspirin microen-

capsules (magnified 50 times ) showing surface

characteristics

FIGURE 2 : Scanning electron micrograph of acetaminophen

microencapsules (magnified 50 times) showing

surface characteristics

FIGURE 3 : Scanning electron micrograph of pseudoephedrine

hydrochloride ( magnified 50 times) microencapsules

showing surface characteristics

FIGURE 4 : Differential scanning calorimeter thermogram of

non microencapsulated acetaminophen ( 1 ),

diphenhydramine hydrochloride (2) and 1:1

physical mixture. ( 3 )

FIGURE 5 : Differential scanning calorimeter thermogram of

microencapsulated acetaminophen (1), diphen

hydramine hydrochloride ( 2 ) and 1: 1 mixture.( 3 )---a-----25

FIGURE 6 : Differential scanning calorimeter thermogram of

non microencapsulated acetaminophen (1),

phenylephrine hydrochloride ( 2 ) and $1: 1$ mixture---------------27

FIGURE 7 : Differential scanning calorimeter thermogram of

microencapsulated acetaminophen ( 1 ), phenyl-

ephrine hydrochloride ( 2 ) and $1: 1$ mixture- 
FIGURE 8 : Comparision of the dissolution profiles of non micro encapsulated and microencapsulated acetaminophen tablets at room temp. in presence of aluminum hydroxide.-----34

FIGURE 9 : Comparision of the dissolution profiles of non microencapsulated and microencapsulated acetaminophen tablets at elevated temperature in presence of aluminum hydroxide.

FIGURE 10 : Comparision of the dissolution profiles of non microencapsulated and microencapsulated acetaminophen tabletsat room temperature in presence of calcium carbonate

FIGURE 11 : Comparision of the dissolution profiles of non microencapsulated and microencapsulated acetaminophen tablets at elevated temperature in presence of calcium carbonate. 40

FIGURE 12 : Comparision of the dissolution profiles of nonmicroencapsulated and microencapsulated acetaminophen tablets at room temperature in presence of magnesium trisilicate.

FIGURE 13 : Comparision of the dissolution profiles of non microencapsulated and microencapsulated acetaminophen tablets at elevated temperature in presence of magnesium trisilicate 
FIGURE 1 : Calibration curve of non - microencapsulated aspirin.-...........--53

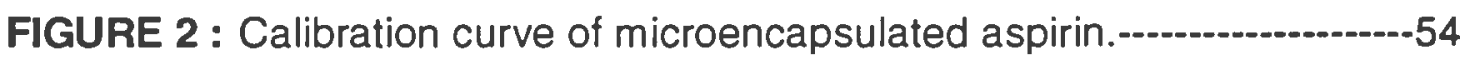

FIGURE 3 : Calibration curve of non - microencapsulated

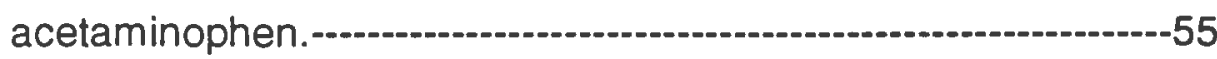

FIGURE 4 : Calibration curve of microencapsulated acetaminophen.---.--.---56

FIGURE 5 : Calibration curve of non - microencapsulated pseudoephedrine hydrochloride.

FIGURE 6 : Calibration curve of microencapsulated pseudoephedrine hydrochloride. $-58$

FIGURE 7 : Scanning electron micrograph of aspirin microencapsules

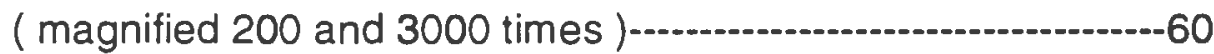

FIGURE 8 : Scanning electron micrograph of acetaminophen

microencapsules. (magnified 200 and 3000 times )

FIGURE 9 : Scanning electron micrograph of pseudoephedrine hydrochloride microencapsules (magnified 200 and 3000 times ) 62 
STUDY OF MICROENCAPSULATED PRODUCTS WITH RESPECT TO THEIR ABILITY TO PREVENT INCOMPATIBILITIES 


\section{ABSTRACT}

The primary objective of this study was to determine the drug interactions and incompatibilities between the drugs and drugs and excipients which have some characteristic compatibility problems. This study included three of such drugs namely aspirin, acetaminophen ( APAP) and pseudoephedrine hydrochloride. It consisted of series of comparative laboratory experiments for the manifestation of incompatibilities or lack thereof in (1) powder mixes and (2) compressed tablets. The selected drugs were used as powders and in the form of microencapsules. The study was conducted at room temperature as well as at $40 \mathrm{C}$ and $60 \% \mathrm{R}$. H. ( relative humidity)

The important degradation pathway for aspirin is hydrolysis. The hydrolysis of aspirin in presence of dibasic calcium phosphate was studied. Aspirin hydrolized producing $39 \%$ degradation at room temperature and $53 \%$ at elevated temperature. In case of microencapsulated aspirin sample, it was 26 $\%$ at room temperature and $28 \%$ at elevated temperature. All samples were analyzed initially and after three months. The avarage salicylic acid build up in both cases was under the pharmacopoeal limits.

The interaction of acetaminophen with various antacids was monitored. The manifestation of interaction was the adsorption of the drug on the antacid. The antacids tested were calcium carbonate (1), aluminum hydroxide ( 2 ) and magnesium trisilicate ( 3 ). In case of non - microencapsulated acetaminophen sample the adsorption of the drugs was found to be $7 \%$ on (1), $18 \%$ on ( 2 ) and $15 \%$ on ( 3 ). In case of microencapsulated acetaminophen sample the adsorption was $2 \%$ on (1), $1.5 \%$ on ( 2 ) and $1.6 \%$ on ( 3 ). The interaction between acetaminophen with diphenhydramine 
hydrochloride and phenylephrine hydrochloride was characterized by melting point depression due to eutectic formation. The eutectic formation was not observed in microencapsulated acetaminophen samples. From these studies conclusion was made that microencapsulated samples showed substantial reduction and in some cases, elimination of the adverse effects of incompatibilities. 


\section{INTRODUCTION}

Microencapsulation may be thought of as a method of wrapping small entities in individual protective coatings 4 . In microencapsulation a relatively thin coating is applied to small particles of solids or droplets of liquids and dispersions. It is arbitrarily differentiated from macroencapsulation in that the former involves the coating of the particles ranging dimmensionally from several tenths of a micrometer to about $5000 \mu .5,6$.

In pharmaceutical preparations the uniqueness of microencapsules lies in the size of the coated particles and their subsequent use and adaptation to a wide variety of dosage forms 8 . Due to the use of these discrete particles, drug moieties can be widely distribiuted throughout the gastrointestinal tract. This potentially improves drug absorption and reduces side effects related to localized build up of irritating drugs against the gastrointestinal mucosa.

In the U.S. A. the majority of the drugs which are in over the couter (OTC) market are combination products 9 . Sometimes the irrational combination of two drugs or drug - excipient leads to a decrease in the stability, bioavailability and efficacy of the dosage form 10 . It has generally been observed that microencapsulated products show a substantial reduction or elimination of the adverse effects of incompatibilities, however the published literature does not appear to have quantitative data substantiating this point.

The compatibility studies mentioned above involved powder mixes and tablet dosage forms owing to the fact that majority of the dosage forms are formulated in the solid state 11 . Any reaction occuring in the solid state will assume dramatically different characteristics from the same reaction 
proceeding under a liquid or gaseous state 12 . Solid state reaction have long maintained a poorly defined terrain on chemical landscape. However difficult to define quantitatively, interactions between solids present a new frontier in the investigation in the chemical behaviour. The primary objective of this study was to determine the drug interactions and incompatibilities between drugs and excipients which are widely used in the pharmaceutical manufacturing and have some characteristic compatibility problems. This study included three of such commercially important drugs. They are aspirin, acetaminophen and pseudoephedrine hydrochloride.

A literatute search has shown that these drugs have some characteristic compatibility problems with commonly used excipients such as dibasic calcium phosphate (Emcompress) $)^{13}$, hydrous lactose 14 ,sodium metabisulphite and magnesium stearate ${ }^{15}$. There is also a sufficient evidence that these drugs interact with other classes of drugs such as antacids, antihistamines and decongestants. This study involved calcium carbonate, aluminum hydroxide and magnesium trisilicate as antacids, diphenhydramine hydrochloride as antihistaminic and phenylephrine hydrochloride as decongestatnt. Solid dosage forms containing aspirin, acetaminophen and pseudoephedrine comprise a significant portion of todays OTC market. Thus it becomes very important to investigate the field of drug interactions occuring in these drugs if they are to be formulated in the solid dosage forms. 


\section{MATERIALS AND METHODS}

This study involved a series of comparative laboratory experiments for the manifestation of incompatibilities or lack thereof in
a) Powder mixes
b) Direct compression tablets.

The selected drugs were used as powders and in the form of microencapsules. The laboratory investigation was made in four types of systems for each drug.

a) Powder mixes using non - microencapsulated drug.

b) Powder mixes using microencapsulated drug.

c) Compressed tablets made using non - microencapsulated drug.

d) Compressed tablets made using microencapsulated drug.

The non - microencapsulated and microencapsulated drugs were obtained from Eurand America, Vandalia, Ohio. All other materials were purchased from commercial sources, mainly from Fisher Scientific, Springfield, New Jersey. All other solvents and reagents used were of HPLC grade.

The powders and tablets of the three drugs were evaluated at the time of preparation in terms of potency, flowability, appearance, hardness, friability, weight variation and content uniformity. They were also evaluated at intervals during storage at ambient temperature and also at $400 \mathrm{C} / 60 \%$ relative 
humidity for a period of eight weeks in order to determine the ralative rate of change between both the types of systems.

The following methods were used for the camparision of microencapsulated and non - microencapsulated formulations.

\section{1) Macroscopic evaluation:}

Samples were subjected to visual observation in triplicate. The macroscopic observation was done for the determination of possible changes in crystalinity, liquifaction, hygroscopicity etc.

\section{2) Dissolution tests:}

Dissolution tests were carried out by using Vanderkamp dissolution test apparatus with standard USP basket assembly. The dissolution medium was distilled water and the studies were done at $37^{\circ} \mathrm{C}$. at $100 \mathrm{RPM}$.

\section{3) Ultra Violet Spectroscopy (UV):}

Ultra violat spectroscopy was used to monitor the interaction between aspirin and dibasic calcium phosphate (Emcompress). It was also used for the quantification of the interaction between acetaminophen and various antacids. The antacids used were aluminum hydroxide, calcium carbonate and magnesium trisilicate.

For the intercation between aspirin and dibasic calcium phosphate, the samples were prepared by mixing equal portions of aspirin and Emcompress. They were then mixed in a turbula mixer for about one hour. Portions of 200 mg. were taken in $5 \mathrm{ml}$. open vials. The vials were placed in constant temperature and relative humidity $\left(45^{\circ} \mathrm{C}\right.$. and $55 \% \mathrm{R}$. H. ). They were then 
removed initially and then at at regular time intervals and analyzed spectrophotometrically in $95 \%$ ethanol at $302 \mathrm{~nm}$.

The validation of the assay was done in order to determine the content of salicylic acid which is a degradation product of aspirin hydrolysis. The method employed was as follows. UV absorbance spectra of aspirin and salicylic acid were obtained for determination of their respective lambda max. They were 258 and $302 \mathrm{~nm}$. respectively. Samples were removed initially and then at regular time intervals. They were diluted appropriately with ethanol and analyzed spectrophotometrically by Hawlett Peckard 8451 A diode array spectrophotometer. The amount of salicylic acid formed was determined by the method of simultaneous equations using molar absorptivities.

Elaborate study was performed on the interaction of acetaminophen with different antacids. The UV determination was done as follows. A standard calibration curve was plotted for both, the microencapsulated and non microencapsulated acetaminophen each time befor the intercation with each antacid. Specific amount of drug solution was mixed with antacid and was rotated in a rotating assembly at $37{ }^{\circ} \mathrm{C}$. at $60 \mathrm{RPM}$. The contents were filtered by nylon 6 filter membrane with a pore soze of $0.45 \mu$.and analyzed spectrophotometrically at $244 \mathrm{~nm}$. Blank correction was done each time and for each antacid to eliminate the influence of water soluble impurities present in the antacid. Attempt was made to determine if there is prevention or decrease in adsorption due to microencapsulation. 


\section{4) Differential Scanning Calorimetry (DSC):}

Differential scanning calorimetry was used for the determination of the interaction between acetaminophen and diphenhydramine hydrochloride and acetaminophen and phenylephrine hydrochloride. Work was done upon both, microencapsulated and non-microencapsulated acetaminophen. The instrumentation was Perkin Elmer DSC - 2 with Linear 1200 chart recorder. The heating rate was $5^{\circ} \mathrm{C} / \mathrm{min}$. and the temperature range was $30^{\circ} \mathrm{C}$. to $250^{\circ} \mathrm{C}$. The chart speed was $2 \mathrm{~cm} / \mathrm{sec}$. and the sensetivity of the instrument was $10 \mathrm{~m}$. cal. / deg. The experiment was carried our in an inert atmosphere with the supply of nitrogen gas. About $25 \mathrm{mg}$. of sample was subjected to DSC each time. The content uniformity of the samples were determined by the endothermic peaks obtained. The results were obtained in duplicates. The manifestation of interaction between acetaminophen and above mentioned drugs was melting point depression due to the formation of eutectic mixture. Attempt was made to determine if there is prevention or decrease in the severity of the interaction due to microencapsulation.

\section{5) Scanning Electron Microscopy ( SEM):}

The microencapsules of aspirin, acetaminophen and pseudoephedrine were mounted on a carbon tape and sputter coated with Gold : Palladium ( $60: 40$ ) in an Edward's S150 B sputtum coater. The analysis was done by examining the samples in the scanning mode with a JEOL 1200 EX scanning / transmission electron microscope operating at $60 \mathrm{KV}$. 
6) Statistical Evaluation:

Statistical evaluation of the interaction between aspirin and dibasic calcium phosphate was done using Student's $t$ test with a $\alpha$ value of 0.01 . The evaluation of the interaction between the acetaminophen and various antacids was done by using Analysis Of Variance ( ANOVA). 


\section{RESULTS}

Figure 1 to 3 shows the scanning electron micrographs (SEM) of the microencapsules of aspirin, acetaminophen and pseudoephedrine hydrochloride respectively.

Fig. 1 gives the micrograph of aspirin, characterized by regular needle shaped crystals ranging from 500 to 2000 microns in length and 25 to 200 microns in width. The coat over these crystals is evident as seen in the photograph. We also found some small irregular crystals clustered in a group between the large needle shaped crystals. Some surface irregularities are also seen in the micrograph.

Fig. 2 gives SEM of microencapsulated acetaminophen. The sample is charecterized by small irregular crystals clustered in a group. The average size ranges from 100 to 500 microns in length and about 50 to 300 microns in width. The coating over the crystals appear to be thick and smooth.

Figure 3 represents SEM of pseudoephedrine hydrochloride. The sample consists of needle shaped round and irregular crystals ranging from 100 to 750 microns in length. The coating of the encapsulating material is seen clearly from the photograph.SEM profile analysis was done at 50, 200 and 3000 times magnification.

Figure 4 shows differential scanning thermogram of non - microencapsulated acetaminophen ( 1 ), diphenhydramine hydrochloride ( 2 ) and $1: 1$ physical mixtre. Non - microencapsulated acetaminophen showed a characteristic 
endothermic peak at $172^{\circ} \mathrm{C}$. Diphenhydramine hydrochloride showed a peak at $167 \circ \mathrm{C}$. When 1: 1 physical mixture was subjected to DSC, the endothermic peak is observed at $98^{\circ} \mathrm{C}$. Figure 5 shows differential scanning thermogram for the microencapsulated acetaminophen (1), diphenhydramine hydrochloride ( 2 ) and 1:1 physical mixture ( 3 ). The microencapsulated acetaminophen showed an endothermic peak at $173^{\circ} \mathrm{C}$. The $1: 1$ physical mixture showed broad endothermic peak between 143 to $146{ }^{\circ} \mathrm{C}$.Figure 6 shows DSC thermogram for the acetaminophen - phenylephrine hydrochloride combination. It shows an endothermic peak at $172{ }^{\circ} \mathrm{C}$ for non microencapsulated acetaminophen ( 1 ), $147{ }^{\circ} \mathrm{C}$ for phenylephrine hydrochloride ( 2 ) and $122{ }^{\circ} \mathrm{C}$ for $1: 1$ physical mixture (3)

Figure 7 represents the DSC thermogram when acetaminophen is microencapsulated. The micrpencapsulated acetaminophen showed a peak at $172^{\circ} \mathrm{C} .1: 1$ physical mixture showed endothermic peak at $152^{\circ} \mathrm{C}$.

Table 1 shows percentage degradation of aspirin in presence of dibasic calcium phosphate in powder mixes. The concentration range was $5 \mu \mathrm{g} / \mathrm{ml}$. to $25 \mu \mathrm{g} / \mathrm{ml}$ The mean percentage degradation was found to be $42 \%$ at room temperature and $54 \%$ at elevated temperature for non microencapsulated aspirin. For aspirin microencapsules the values were $27 \%$ and $33 \%$ respectively. The two treatments were compared using Student's t test.( Table 4 ). The $p$ value for this statistic was found to be 0.004 indicating that the probability that there is no difference between the two data sets is 0.004 .

Table 2 shows percentage degradation of aspirin in presence of Emcompress in direct compression tablets. Same concentration range as in case of powder 
mixes was selected. The mean percentage degradation in this case was found to be $39 \%$ at room temperature and $53 \%$ at elevated temperature when non- microencapsulated aspirin was used. In case of microencapsulated aspirin the values were $26 \%$ and $28 \%$ respectively. When the two treatments were compared with Student's $t$ test ( Table 4 ). The $p$ value was found to be $0.006 \%$.

Figure 8 shows the dissolution profile of non-microencapsulated and microencapsulated acetaminophen tablets at room temperature in presence of aluminum hydroxide. Figure 9 shows the dissolution profile of non microencapsulated and microencapsulated acetaminophen tablets at elevayed temperature in presence of aluminum hydroxide. For non microencapsulated acetaminophen, the percentage dissolution after 45 mins.was $78 \%$ for the samples kept at room temperature and $82 \%$ for samples kept at elevated temperature. For microencapsulated acetaminoiphen the values were found to be $94 \%$ and $95 \%$ respectively. As seen from figures 8 and 9, all the profiles were compared with acetaminophen control.

Figure 10 shows dissolution profile of non-microencapsulated and microencapsulated acetaminophen tablets at room temperature in presence of calcium carbonate. Non - microencapsulated acetaminophen showed $89 \%$ dissolution for samples kept at room temperature and $90 \%$ dissolution for samples stored at elevated temperature. Figure 11 shows dissolution profile of non - microencapsulated and microencapsulated acetaminophen tablets at elevated temperature in presence of calcium carbonate. For microencapsulated acetaminophen the percentage dissolution was $94 \%$ for samples stored at room temperature and $97 \%$ for the samples stored at 
elevated temperature. Both the dissolution profiles were compared with acetaminophen control.

Figure 12 shows dissolution profile of non - microencapsulated and microencapsulated acetaminophen tablets at room temperature in presence of magnesium trisilicate. The percentage dissolution was $82 \%$ for the samples kept at room temperature and $83 \%$ for the samples kept at elevated temperature. Figure 13 shows dissolution profile of non-microencapsulated and microencapsulated acetaminophen tablets at elevated temperature in presence of magnesium trisilicate. Microencapsulated acetaminophen showed $94 \%$ dissolution for the samples kept at room temperature and $94 \%$ dissolution for the samples kept at elevated temperature. Both the dissolution profiles were compared with acetaminophen control.

Table 3 shows the interaction of acetaminophen with different antacids in the powder mixes. In case of non microencapsulated acetaminophen and aluminum hydroxide powder mix the percentage of drug adsorbed over the antacid was found $14 \%$. Use of microencapsulated acetaminophen decreased this adsorption to $4 \%$. Similarly for non - microencapsulated and microencapsulated acetaminophen with aluminum hydroxide mix the values were $5 \%$ and $2 \%$ respectively. When the antacid was magnesium trisilicate, the values were $24 \%$ and $8 \%$ respectively. The statistical evaluation of these interactions was done by using ANOVA. (Analysis of Variance) Tables 5,6 and 7 shows the results obtained form ANOVA. 


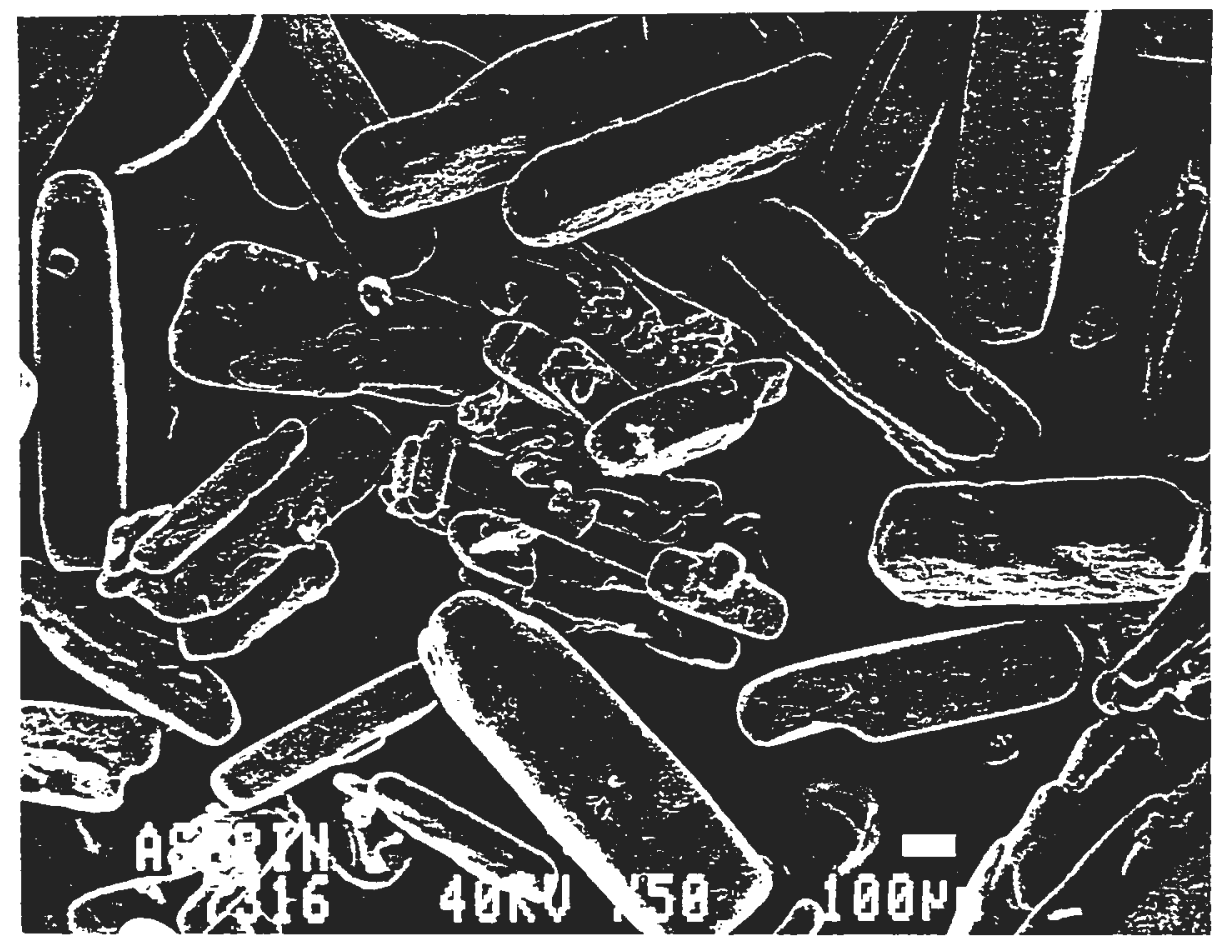

FIGURE 1 Scanning electron micrograph of the crystals of microencapsulated aspirin ( magnified 50 times ) taken with a JEOL 1200 EX electron microscope. 


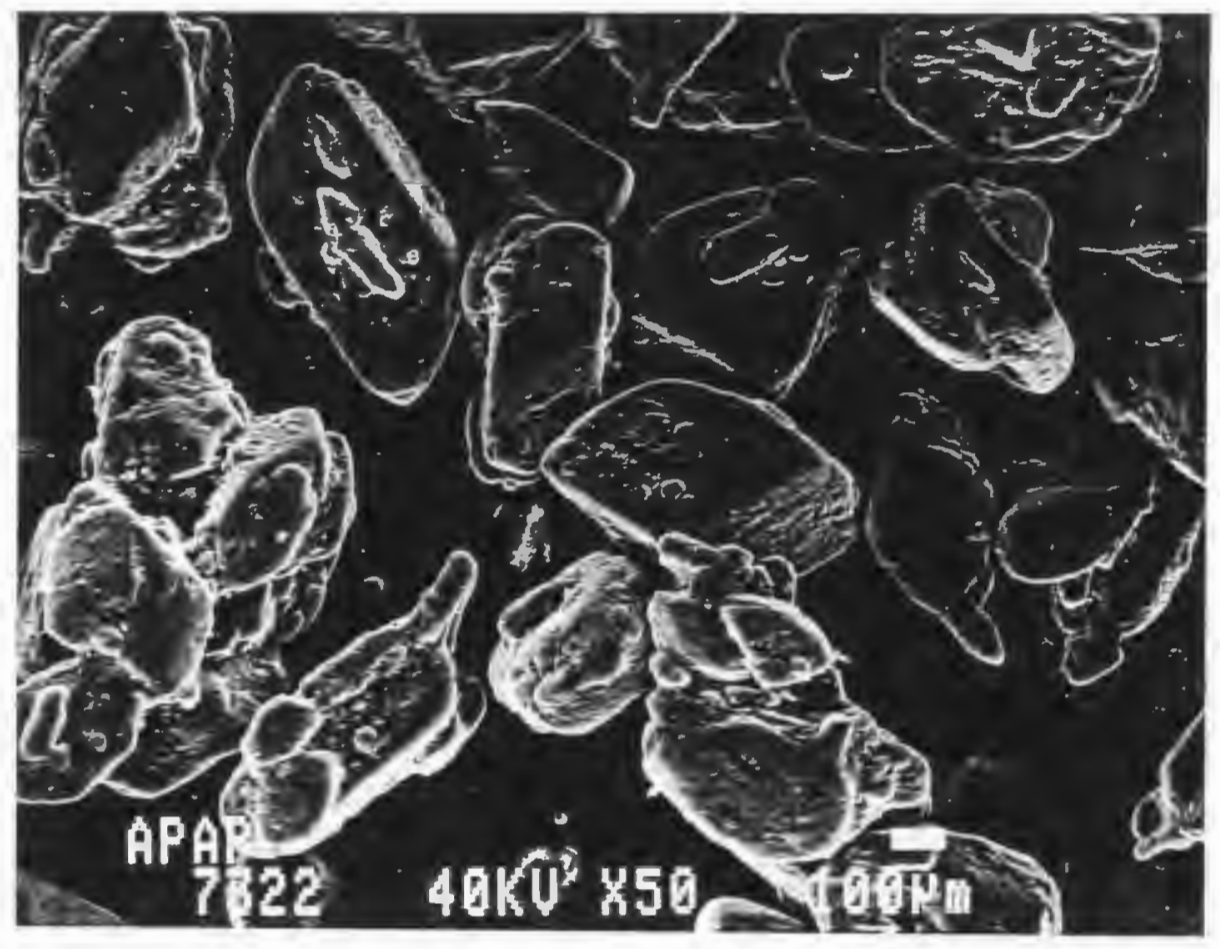

FIGURE 2 Scanning electron micrograph of the crystals of microencapsulated acetaminophen (magnified 50 times) taken with a JEOL 1200 EX electron microscope. 


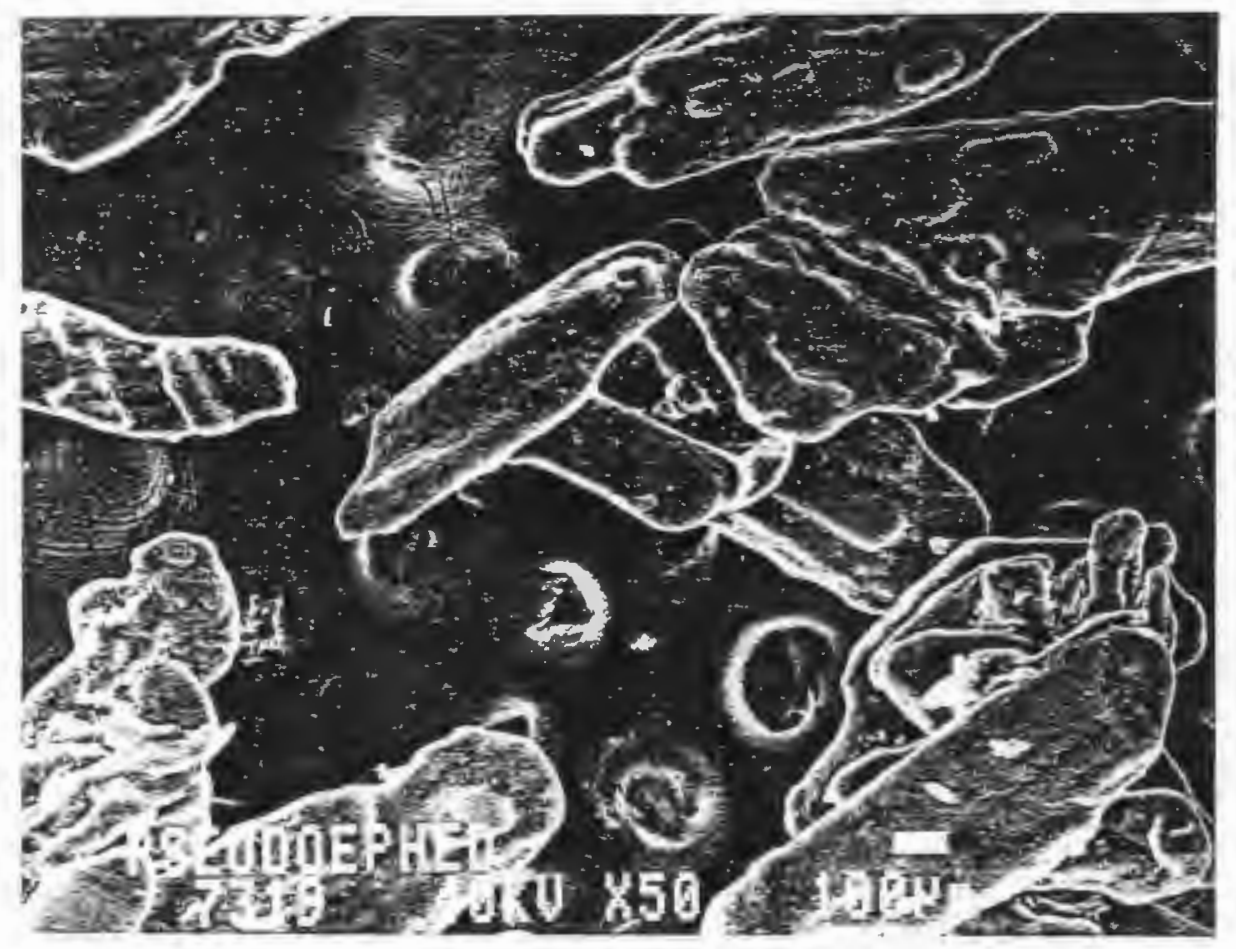

FIGURE 3 Scanning electron micrograph of the crystals of microencapsulated pseudoephedrine hydrochloride ( magnified 50 times ) taken with a JEOL 1200 EX electron microscope. 
TABLE 1 Percentage degradation of aspirin in presence of dibasic calcium phosphate (Emcompress) in powder mixture :

\begin{tabular}{|l|l|l|l|l|}
\hline Concentration & $\begin{array}{l}\text { Non micro - } \\
\text { encapsulated } \\
\text { aspirin }\end{array}$ & $\begin{array}{l}\text { Non micro - } \\
\text { encapsulated } \\
\text { aspirin }\end{array}$ & $\begin{array}{l}\text { Aspirin micro- } \\
\text { encapsules }\end{array}$ & $\begin{array}{l}\text { Aspirin micro- } \\
\text { encapsules }\end{array}$ \\
\hline Samples at & $\begin{array}{l}\text { samples at } \\
\text { elevated temp. }\end{array}$ & $\begin{array}{l}\text { room temp. } \\
\text { room temp. }\end{array}$ & $\begin{array}{l}\text { elevated temp. } \\
\text { samples at }\end{array}$ \\
\hline $5 \mu \mathrm{g} / \mathrm{ml}$. & $43 \%$ & $55 \%$ & $37 \%$ & $40 \%$ \\
\hline $10 \mu \mathrm{g} . / \mathrm{ml}$. & $48 \%$ & $59 \%$ & $25 \%$ & $33 \%$ \\
\hline $15 \mu \mathrm{g} . / \mathrm{ml}$. & $36 \%$ & $47 \%$ & $21 \%$ & $28 \%$ \\
\hline $20 \mu \mathrm{g} . / \mathrm{ml}$. & $44 \%$ & $51 \%$ & $24 \%$ & $30 \%$ \\
\hline $25 \mu \mathrm{g} . / \mathrm{ml}$. & $39 \%$ & $49 \%$ & $27 \%$ & $25 \%$ \\
\hline Mean & $424 \%$ & $54.8 \%$ & $27.1 \%$ & $33.5 \%$ \\
\hline S. D. & 9.2 & 11.2 & 6.2 & 6.2 \\
\hline
\end{tabular}


TABLE 2 : Percentage degradation of aspirin in presence of dibasic calcium phosphate (Emcompress) in direct compression tablets:

\begin{tabular}{|c|c|c|c|c|}
\hline Concentration & $\begin{array}{l}\text { Non micro - } \\
\text { encapsulated } \\
\text { aspirin }\end{array}$ & $\begin{array}{l}\text { Non micro - } \\
\text { encapsulated } \\
\text { aspirin }\end{array}$ & $\begin{array}{l}\text { Aspirin micro - } \\
\text { encapsules }\end{array}$ & $\begin{array}{l}\text { Aspirin micro - } \\
\text { encapsules }\end{array}$ \\
\hline & $\begin{array}{l}\text { Samples at } \\
\text { room temp. }\end{array}$ & $\begin{array}{l}\text { Samples at } \\
\text { elevated temp. }\end{array}$ & $\begin{array}{l}\text { Samples at } \\
\text { room temp. }\end{array}$ & $\begin{array}{l}\text { Samples at } \\
\text { elevated temp. }\end{array}$ \\
\hline $5 \mu \mathrm{g} . / \mathrm{ml}$. & $42 \%$ & $55 \%$ & $31 \%$ & $40 \%$ \\
\hline $10 \mu \mathrm{g} . / \mathrm{ml}$. & $41 \%$ & $57 \%$ & $35 \%$ & $33 \%$ \\
\hline $15 \mu \mathrm{g} . / \mathrm{ml}$. & $34 \%$ & $55 \%$ & $20 \%$ & $29 \%$ \\
\hline $20 \mu \mathrm{g} . / \mathrm{ml}$. & $38 \%$ & $49 \%$ & $20 \%$ & $27 \%$ \\
\hline $25 \mu \mathrm{g} . / \mathrm{ml}$. & $40 \%$ & $51 \%$ & $25 \%$ & $24 \%$ \\
\hline Mean & $39.1 \%$ & $53.4 \%$ & $26.4 \%$ & $28.1 \%$ \\
\hline S. D. & 6.3 & 8.6 & 10.3 & 11.2 \\
\hline
\end{tabular}


TABLE 3 : Interaction of acetaminophen with various antacids in the powder form

\begin{tabular}{|l|l|}
\hline Combination & Percentage drug adsorbed on antacid \\
\hline $\begin{array}{l}\text { Unencapsulated acetaminophen and } \\
\text { aluminum hydroxide }\end{array}$ & $14 \%$ \\
\hline $\begin{array}{l}\text { Encapsulated acetaminophen and } \\
\text { aluminum hydroxide }\end{array}$ & $4 \%$ \\
\hline $\begin{array}{l}\text { Unencapsulated acetaminophen and } \\
\text { calcium carbonate }\end{array}$ & $5 \%$ \\
\hline $\begin{array}{l}\text { Encapsulated acetaminophen and } \\
\text { calcium carbonate }\end{array}$ & $2 \%$ \\
\hline $\begin{array}{l}\text { Unencapsulated acetaminophen and } \\
\text { magnesium trisilicate }\end{array}$ & $24 \%$ \\
\hline $\begin{array}{l}\text { Encapsulated acetaminophen and } \\
\text { magnesium trisilicate }\end{array}$ & $8 \%$ \\
\hline
\end{tabular}


TABLE 4 : Student's $t$ test for microencapsulated and non - microencapsulated aspirin in presence of Emcompress

a) Powder mixes

Non - microencapsulated Vs microencapsulated at room temperature

\begin{tabular}{|l|l|l|l|}
\hline Deg. of Freedom & Mean $X-Y$ & Paired $t$ value & Prob. (2 - tail) \\
\hline 4 & 15.2 & 5.084 & 0.0071 \\
\hline
\end{tabular}

Non-microencapsulated Vs microencapsulated at elevated temperature.

\begin{tabular}{|l|l|l|l|}
\hline Deg. of Freedom & Mean $X-Y$ & Paired t value & Prob. (2 - tail) \\
\hline 4 & 21 & 10.917 & 0.0004 \\
\hline
\end{tabular}

b ) Direct compression tablets

Non - microencapsulated $V s$ microencapsulated at room temperature

\begin{tabular}{|l|l|l|l|}
\hline Deg. of Freedom & Mean $X-Y$ & Paired $t$ value & Prob (2 - tail ) \\
\hline 4 & 12.8 & 6.291 & 0.0033 \\
\hline
\end{tabular}

Non - microencapsulated Vs microencapsulated at elevated temperature

\begin{tabular}{|l|l|l|l|}
\hline Deg. of Freedom & Mean $X-Y$ & Paired $t$ value & Prob (2 - tail $)$ \\
\hline 4 & 22.8 & 10.701 & 0.004 \\
\hline
\end{tabular}


FIGURE 4 Differential scanning calorimeter thermogram of non microencapsulated acetaminophen ( labelled as 1), Diphenhydramine hydrochloride (Labelled as 2 ) and $1: 1$ physical mixture of the two drugs. (labelled as 3). The scale at the bottom shows temperature in degree centigrades. 

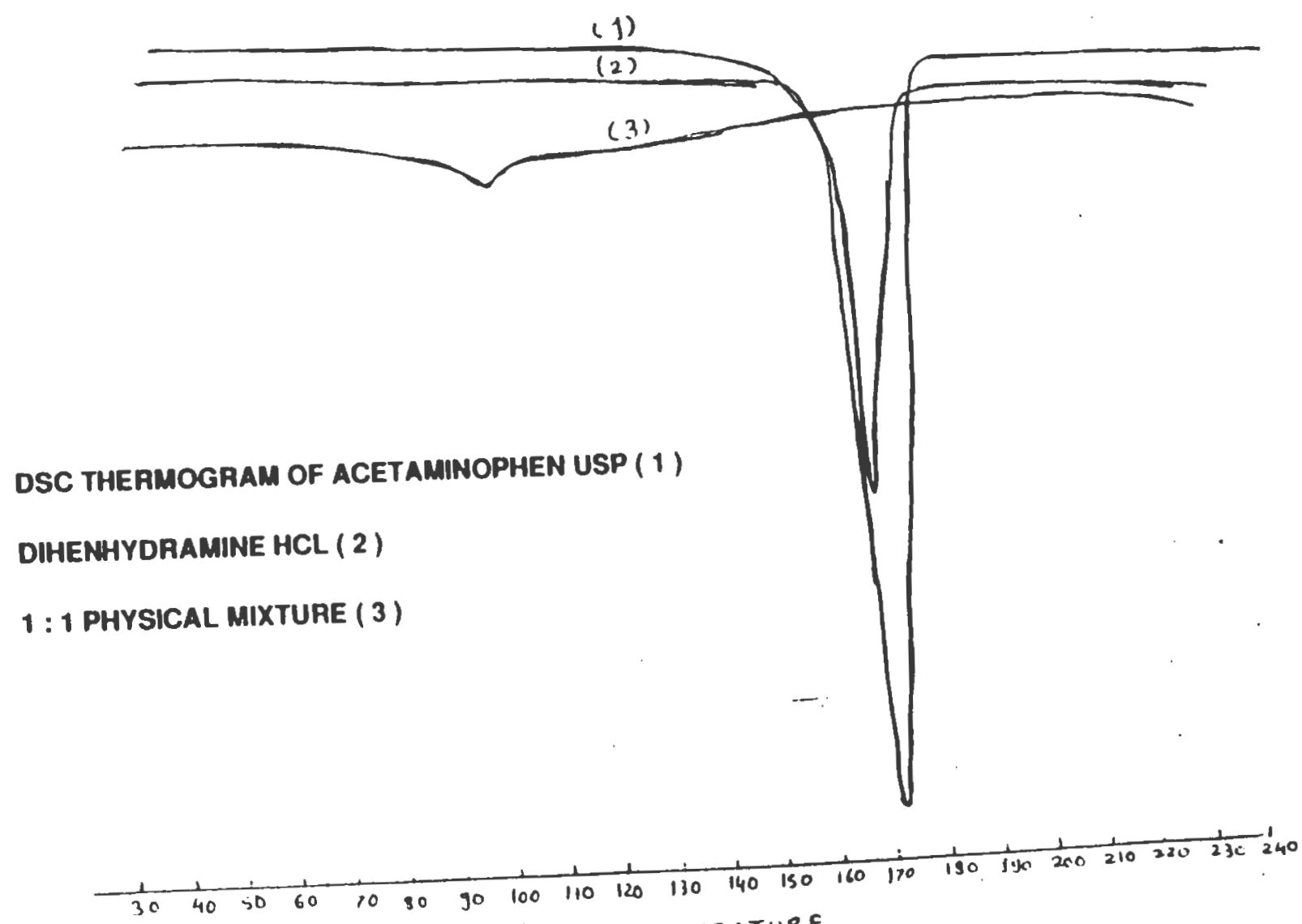

TEMPERATURE 
FIGURE 5 Differential scanning calorimeter thermogram of microencapsulated acetaminophen (labelled as 1), Diphenhydramine hydrochloride (Lebelled as 2) and $1: 1$ physical mixture of the two drugs. (labelled as 3). The scale at the bottom shows temperature in degree centigrades. 


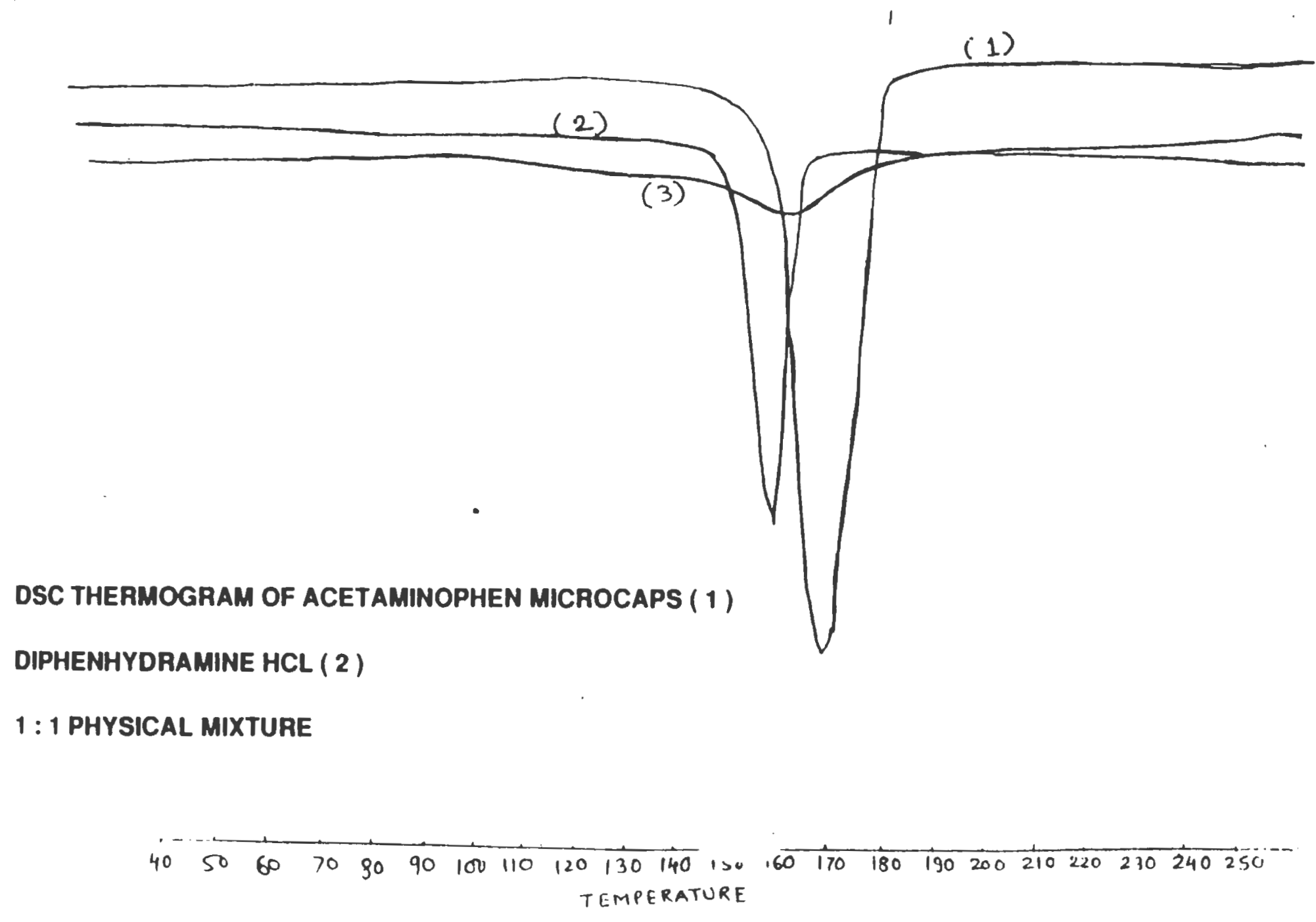


FIGURE 6 Differential scanning calorimeter thermogram of non microencapsulated acetaminoiphen (labelled as 1 ), Phenylephrine hydro chloride (labelled as 2 ) and 1: 1 physical mixture (labelled as 3 ). The scale at the bottom shows the temperature in degrees centigrade. 


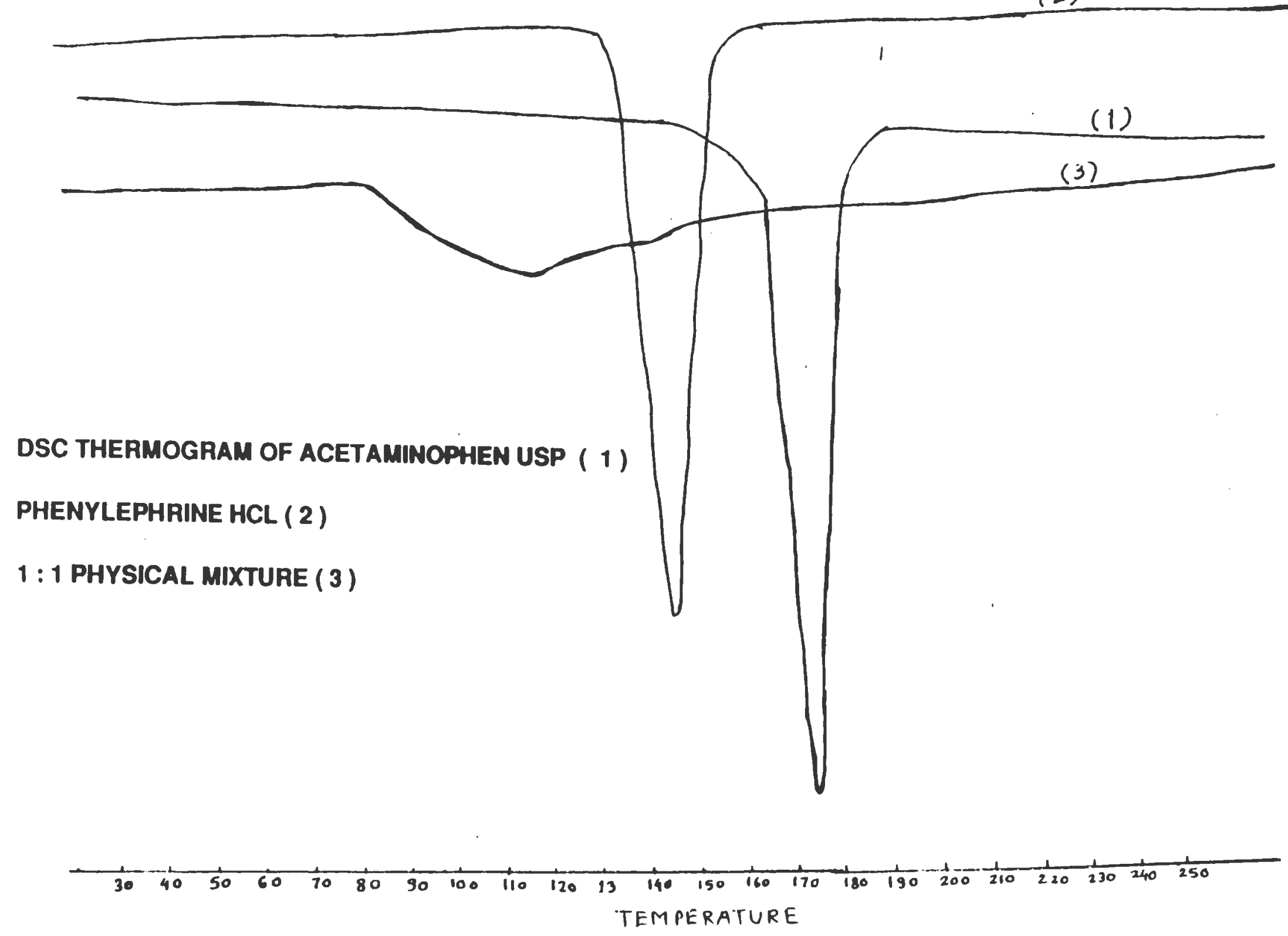


FIGURE 7 Differential scanning calorimeter thermogram of non microencapsulated acetaminoiphen ( labelled as 1 ), Phenylephrine hydro chloride ( labelled as 2 ) and 1:1 physical mixture (labelled as 3 ). The scale at the bottom shows the temperature in degrees centigrade. 


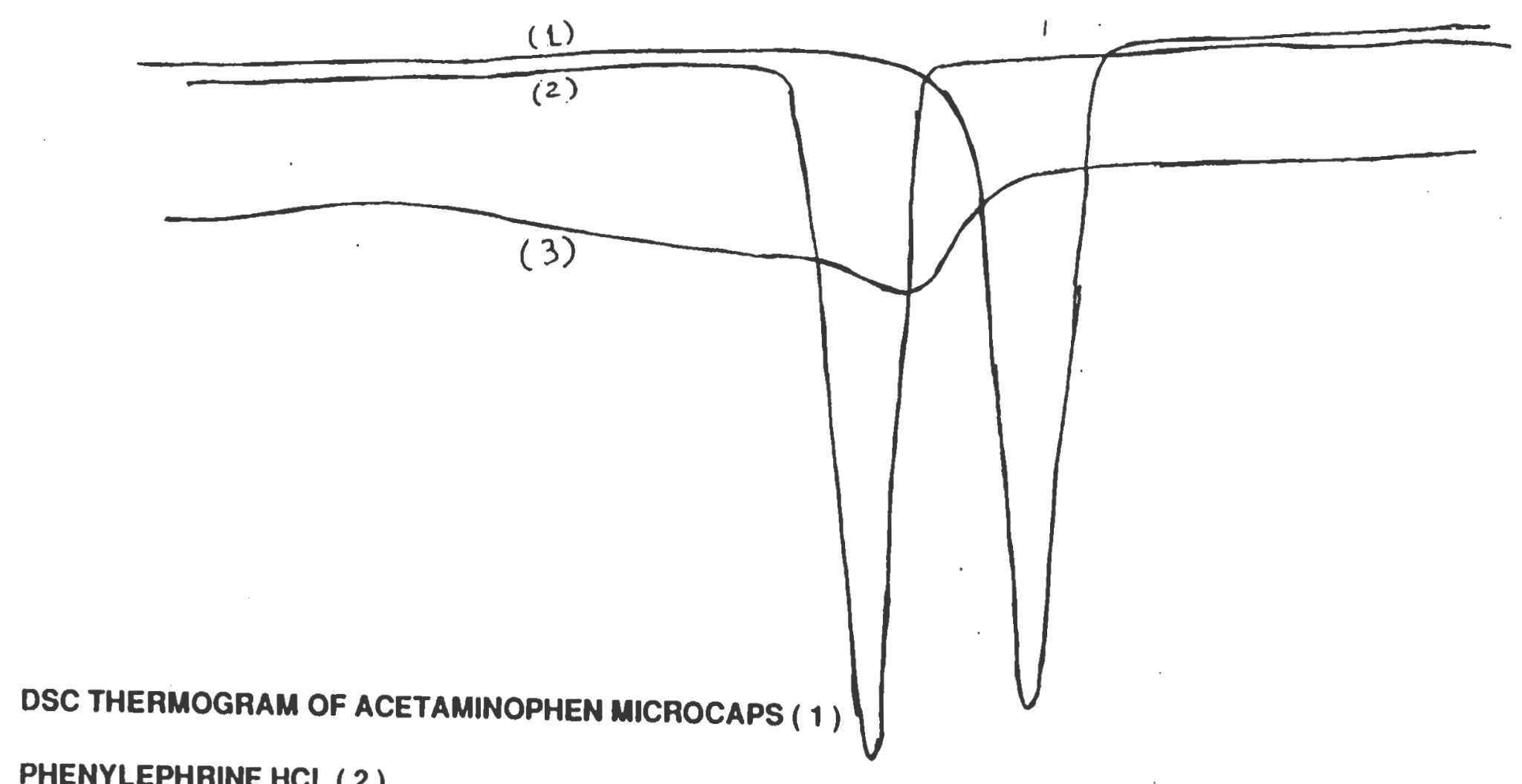

1 : 1 PHYSICAL MIXTURE ( 3 )

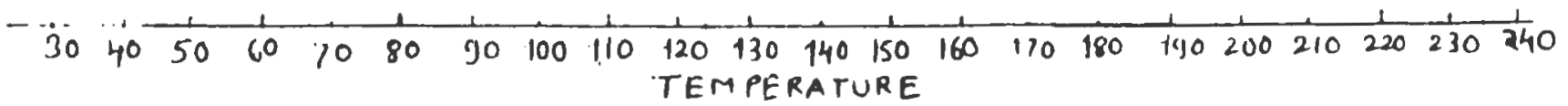


TABLE 5: ANOVA of microencapsulated and non - microencapsulated acetaminophen in presence of aluminum hydroxide

\begin{tabular}{|l|l|l|l|l|l|}
\hline $\begin{array}{l}\text { Source of } \\
\text { variation }\end{array}$ & $\begin{array}{l}\text { Degree of } \\
\text { Freedom }\end{array}$ & $\begin{array}{l}\text { Sum of } \\
\text { squares }\end{array}$ & $\begin{array}{l}\text { Mean } \\
\text { square }\end{array}$ & F value & P value \\
\hline Temperature & 1 & 5.311 & 5.311 & 142.5 & 0.00 \\
\hline Formulation & 1 & 0.113 & 0.113 & 3.045 & 0.0963 \\
\hline TF & 1 & 0.711 & 0.711 & 19.075 & 0.0003 \\
\hline
\end{tabular}


TABLE 6: ANOVA of microencapsulated and non - microencapsulated acetaminophen in presence of calcium carbonate

\begin{tabular}{|l|l|l|l|l|l|}
\hline $\begin{array}{l}\text { Source of } \\
\text { variation }\end{array}$ & $\begin{array}{l}\text { Degree of } \\
\text { Freedom }\end{array}$ & $\begin{array}{l}\text { Sum of } \\
\text { squares }\end{array}$ & $\begin{array}{l}\text { Mean } \\
\text { square }\end{array}$ & F value & P value \\
\hline Temperature & 1 & 0.211 & 0.211 & 9.209 & 0.0065 \\
\hline Formulation & 1 & 0.155 & 0.155 & 6.776 & 0.0065 \\
\hline TF & 1 & 3.912 & 3.912 & 170.8 & 0.00 \\
\hline
\end{tabular}


TABLE 7 : ANOVA of microencapsulated and non - microencapsulated acetaminophen in presence of magnesium trisilicate

\begin{tabular}{|l|l|l|l|l|l|}
\hline $\begin{array}{l}\text { Source of } \\
\text { variation }\end{array}$ & $\begin{array}{l}\text { Degree of } \\
\text { Freedom }\end{array}$ & $\begin{array}{l}\text { Sum of } \\
\text { squares }\end{array}$ & $\begin{array}{l}\text { Mean } \\
\text { square }\end{array}$ & F value & P value \\
\hline Temperature & 1 & 8.821 & 8.812 & 419.0 & 0.00 \\
\hline Formulation & 1 & 0.886 & 0.886 & 42.11 & 0.00 \\
\hline TF & 1 & 0.760 & 0.760 & 36.13 & 0.00 \\
\hline
\end{tabular}


FIGURE 8 Comparision of the dissolution profiles of non microencapsulated and microencapsulated acetaminophen tablets at room temperature in presence of aluminum hydroxide. The abscissa indicates time in minutes and the ordinate shows cumulative percent release of the drug. The acetaminophen control is labelled as APAP CONTROL where as the dissolution profiles of non microencapsulated and microencapsulated acetaminophen are labelled as N. M. AT R. T. and M. AT R. T respectively. 


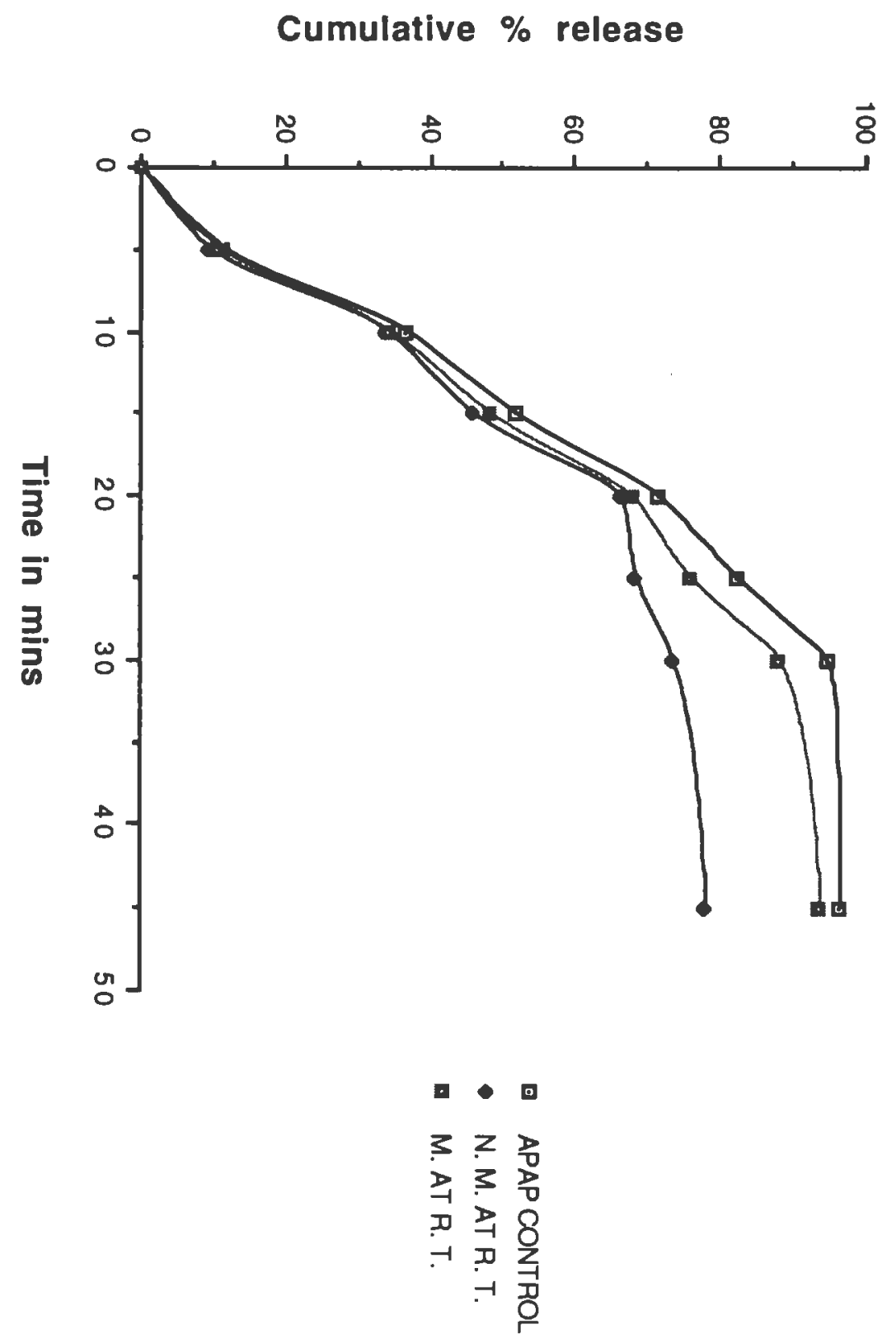


FIGURE 9 Comparision of the dissolution profiles of non microencapsulated and microencapsulated acetaminophen tablets at elevated temperature in presence of aluminum hydroxide. The abscissa indicates time in minutes and the ordinate shows cumulative percent release of the drug.The acetaminophen control is labelled as APAP CONTROL where as the dissolution profiles of non microencapsulated and microencapsulated acetaminophen are labelled as N. M. AT E. T. and M. AT E. T. respectively. 


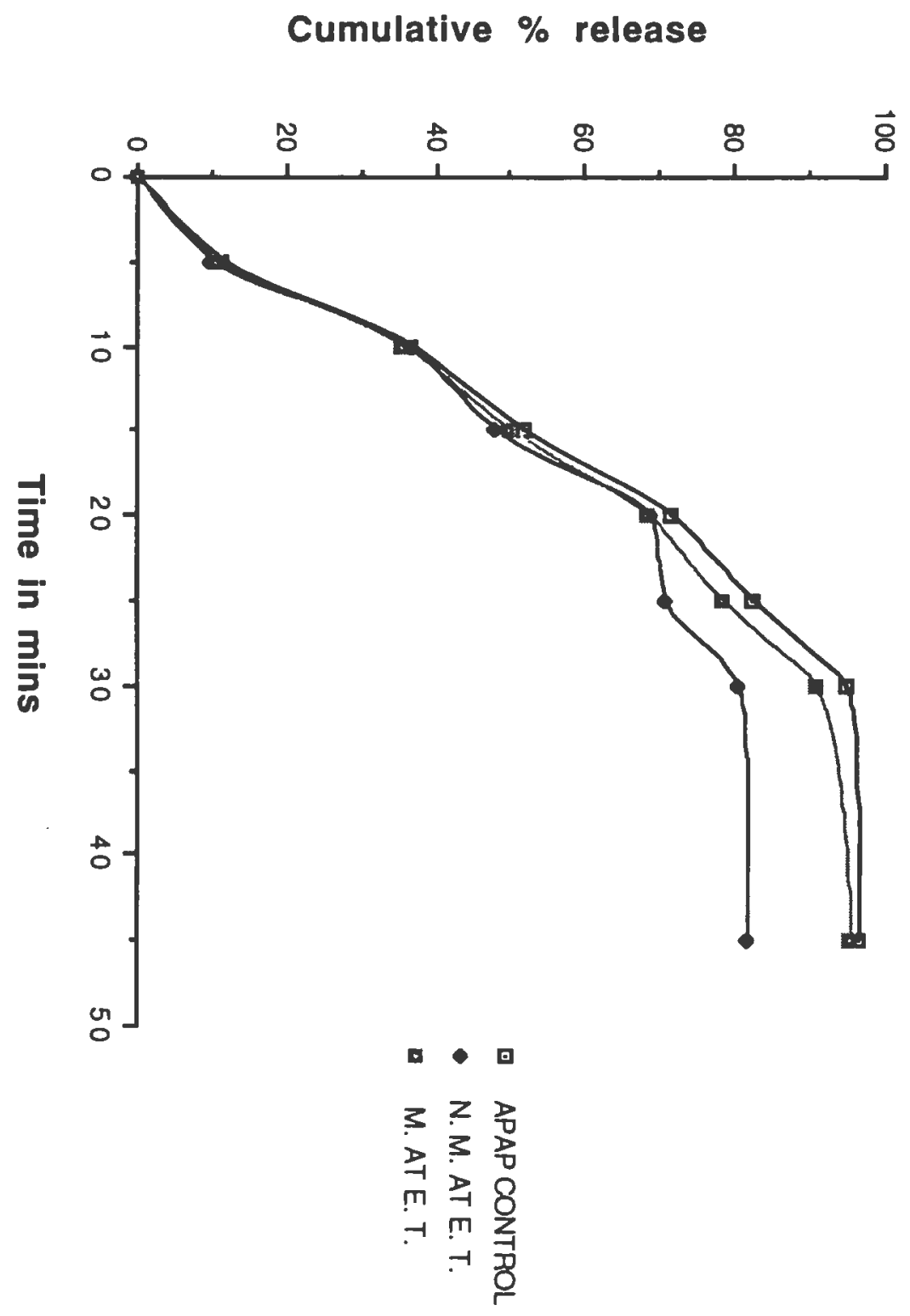


FIGURE 10 Comparision of the dissolution profiles of non microencapsulated and microencapsulated acetaminophen tablets at room temperature in presence of calcium carbonate.The abscissa indicates time in minutes and the ordinate shows cumulative percent release of the drug. The acetaminophen control is labelled as APAP CONTROL where as the dissolution profiles of non microencapsulated and microencapsulated acetaminophen are labelled as N. M. AT R. T. and M. AT R. T. respectively. 


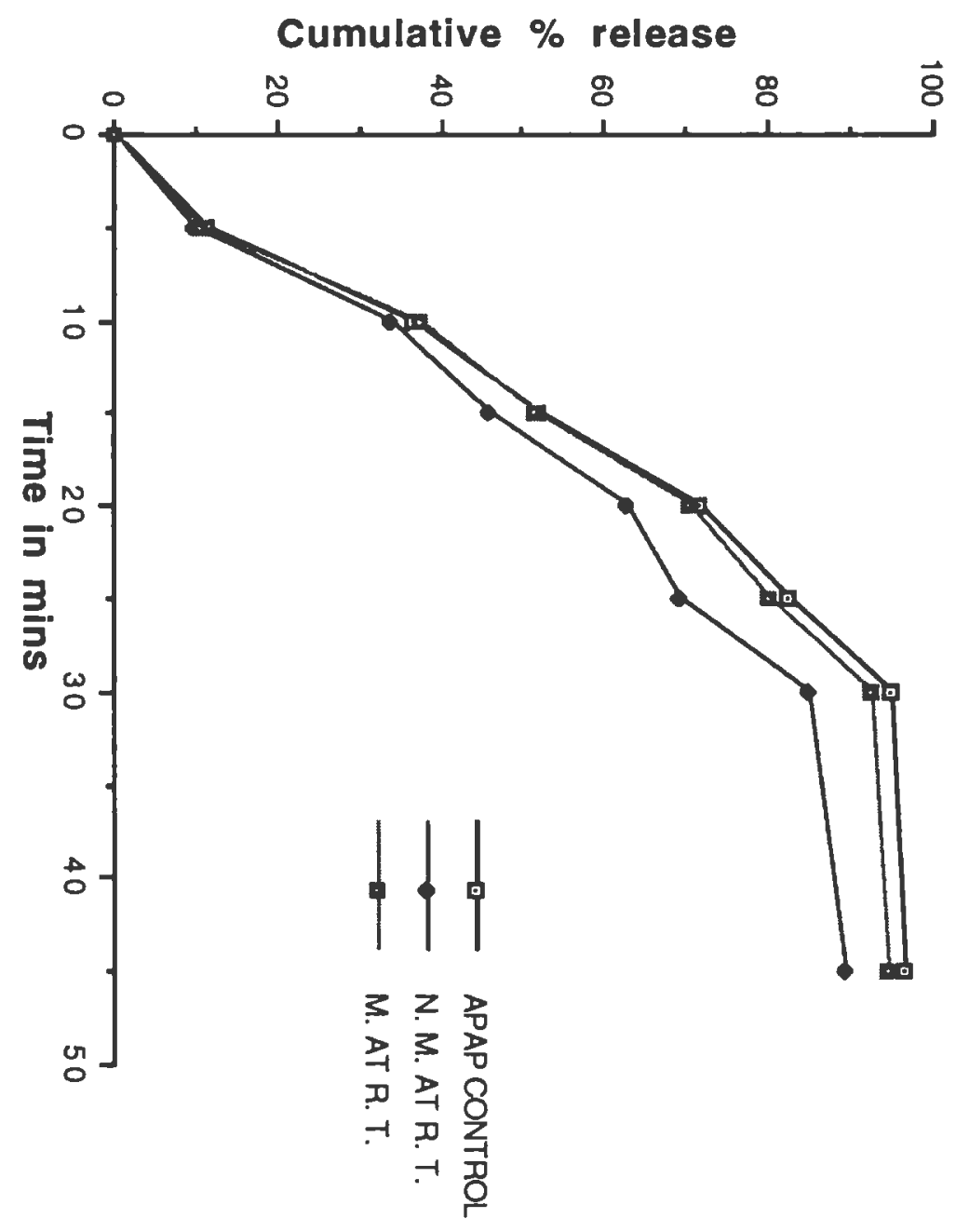


FIGURE 11 Comparision of the dissolution profiles of non microencapsulated and microencapsulated acetaminophen tablets at elevated temperature in presence of calcium carbonate The abscissa indicates time in minutes and the ordinate shows cumulative percent release of the drug. The acetaminophen control is labelled as APAP CONTROL where as the dissolution profiles of non microencapsulated and microencapsulated acetaminophen are labelled as N. M. AT E. T. and M. AT E. T. respectively. 


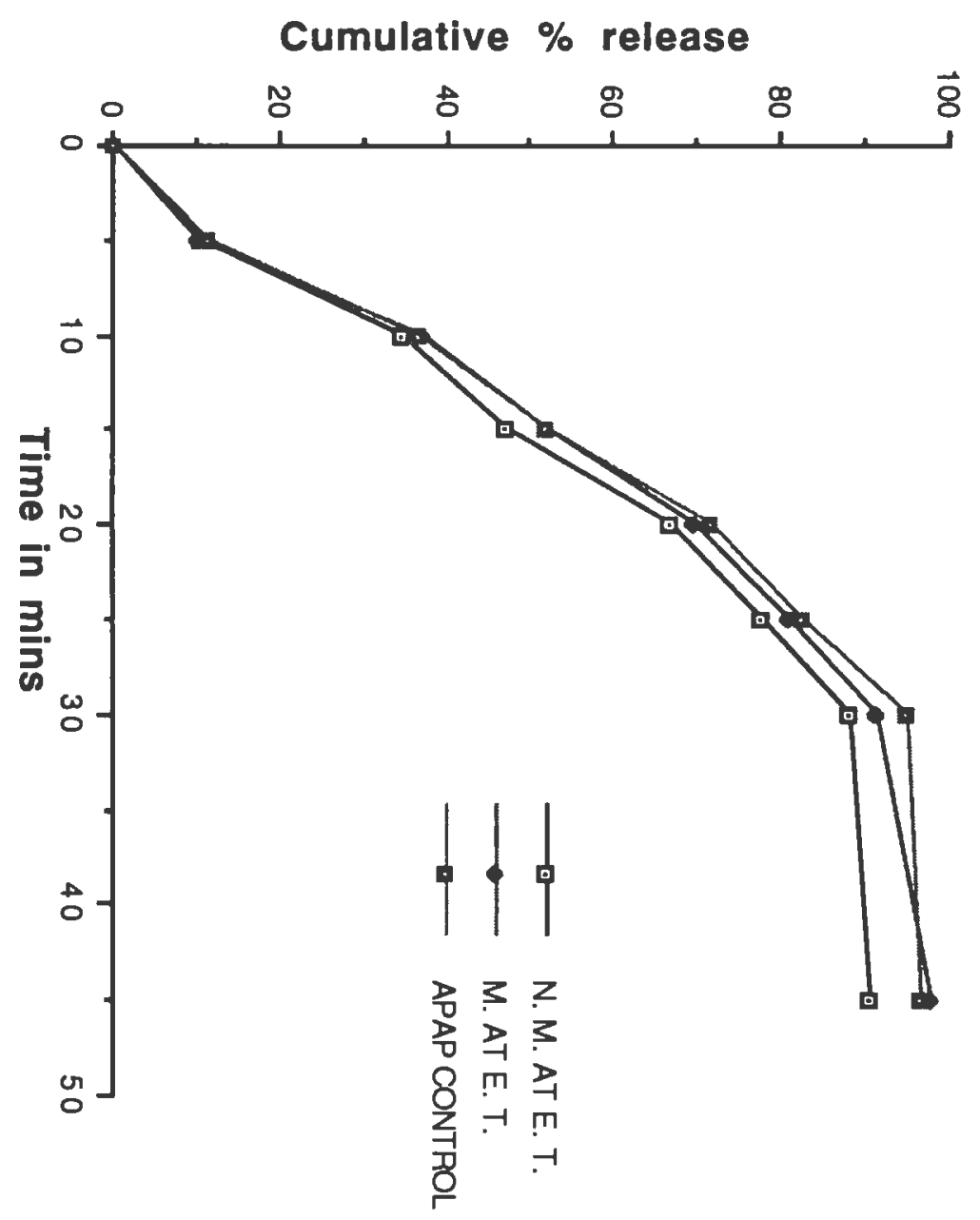


FIGURE 12 Comparision of the dissolution profiles of microencapsulated and non microencapsulated acetaminophen in the tablet form at room temperature in presence of magnesium trisilicate. The abscissa indicates time in minutes and the ordinate shows cumulative percent release of the drug.The acetaminophen control is labelled as APAP CONTROL where as the dissolution profiles of non microencapsulated and microencapsulated acetaminophen are labelled as N. M. AT R. T. and M. AT R. T. respectively. 


\section{Cumulative \% release}

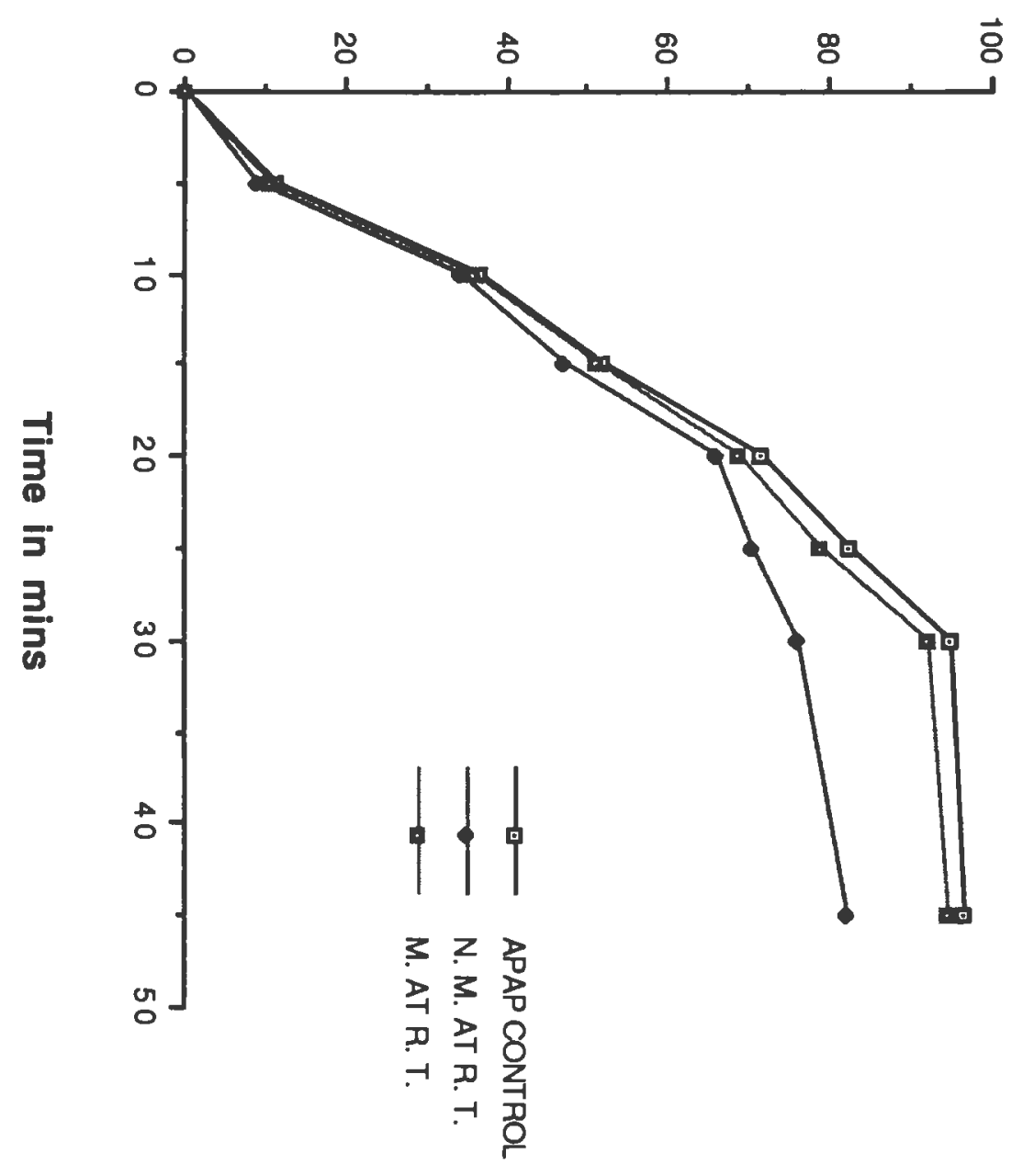


FIGURE 13 Comparision of the dissolution profiles of microencapsulated and non microencapsulated acetaminophen in the tablet form at elevated temperature in presence of magnesium trisilicate. The abscissa indicates time in minutes and the ordinate shows cumulative percent release of the drug. The acetaminophen control is labelled as APAP CONTROL where as the dissolution profiles of non microencapsulated and microencapsulated acetaminophen are labelled as N. M. AT E. T. and M. AT E. T. respectively. 


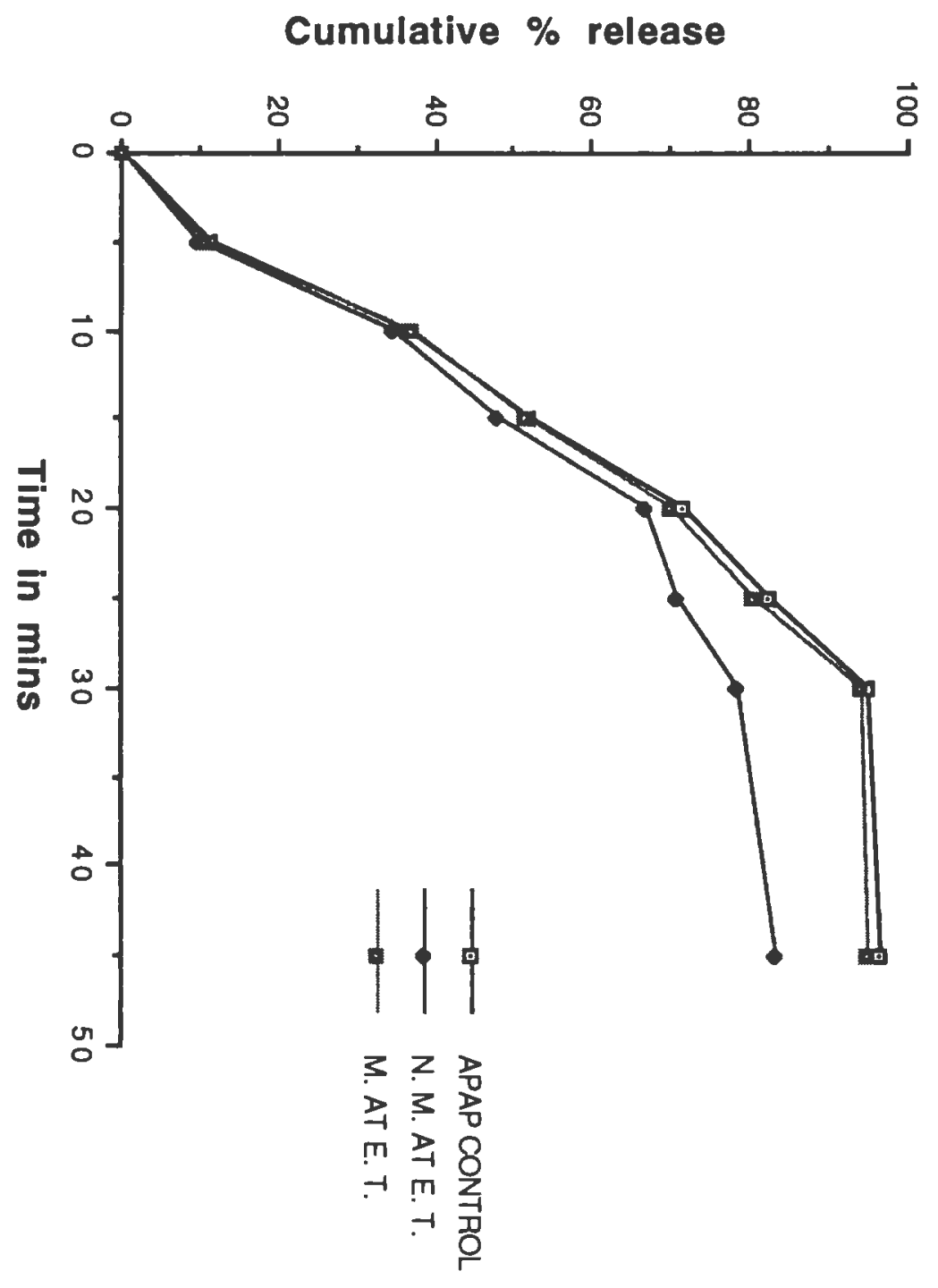




\section{DISCUSSION}

In all the interaction studies carried out, it was demonstrated successfully that the microencapsulated drugs showed substantial reduction of the adverse effects of incompatibilities. The rate of degradation was significantly different for the microencapsulated and non microencapsulated systems. Though literature sources support the concept of enhancement of drug stability due to microencapsulation, there is absence of reliable published quantitative data which proves this point. Lot of material addresses this issue qualitatively. This study was focused on the quantitative aspects of the enhancement of stability due to microencapsulation.

All three drugs examined in this project showed significant stability when incorporated to microencapsules. However the level of protection was found to be different in all three cases. For acetaminophen the degree of protection was greatest followed by pseudoephedrine and aspirin. It was found that the level of protection offered by microencapsulated drugs in compressed tablets was greater than those found in the powder mixes. At the same time, the severity of the interaction was less in case of powders and was greater in case of compressed tablets. In case of tablets it was found that there was no effect of the compaction force on the integrity of the microcapsule coat. This observation could be supported by the fact that the tablets contained large amount of lactose which was used as a tablet matrix. This may have dispersed microencapsules and might have provided a cushioning effect which would protect the microencapsules from rupture during the compaction process. It would be interesting to see the effect of compaction force when the percentage of lactose to the microcapsules gradually decreases i. e. in a 
tablet the amount of lactose goes on decreasing and the amount of drug remains same.

It was also observed that for the three compaction forces selected, the integrity of microcapsules was unaffected. This finding suggests that the Eurand microencapsules are sufficiently robust to be used commercially in compressed tablets without concern for capsule rupture. It may also be interesting to determine the effect of the increase in the percentage of microcapsules over the range of compaction forces.

It was found that the temperature affects significantly the results obtained between microencapsulated and non microencapsulated systems. The effect of time was not that pronounced. This observation was supported by the fact that the samples at elevated temperature were subjected to rigorous stress conditions ( $45^{\circ} \mathrm{C}$ and $60 \%$ relative humidity ).

The decomposition of aspirin is due to hydrolysis which gave salicylic acid as a major hydrolytic product. The interaction takes place at room temperature and the rate of the reaction was enhanced by the increase in the temperature or the presence of moisture. The interaction was monitored in both these conditions. The assay involved the determination of the amount of drug remaining over an interval of time in powder mixes and compressed tablets. The analysis was done by UV at $\lambda$ max. for aspirin. The figures obtained from both the data sets were compared and it was concluded that the degree of protection offered by microencapsulation was more in compressed tablets than in powders.

The interaction of acetaminophen with various antacids was a physical phenomenon of adsorption of the drug over the antacid. As indicated earlier 
the rate of interaction differed significantly in powder form and compressed tablets. It was also found that the degree of adsorption was less at elevated temperature and more at room temperature. This observation can be supported by the fact that adsorption is a physical phenomenon and is affected by kinetics. The increase in temperature may result in the increase in the kinetic energy of the molecules, thereby increasing internal energy facilitating desorption.

It was observed that there is practically no interaction between aspirin and pseudoephedrine combination as well as pseudoephedrine acetaminophen combination. The inertness of the combination was apparent by the UV absorbance readings as well as by physical observations. The stability of the combination was retained at accelerated conditions. As pseudoephedrine itself was found to be stable with aspirin and acetaminophen, the same conclusion holds good for microencapsulated pseudoephedrine as the coating is made up of inert material.

The interactions of aspirin and pseudoephedrine were analyzed using statview statistical package. The method of analysis was Student's two tailed $t$ test. Using this test, the difference in the microencapsulated and non microencapsulated systems was easily demonstrated. The $\alpha$ value for this statistic was 0.01 . The probability term calculated by $t$ test was found very near to 0 indicating there is a very low probability that the results are similar between non microencapsulated and microencapsulated systems. 


\section{CONCLUSIONS}

The conclusions made from the drug interaction studies can be enumarated as follows.

1 ) Aspirin showed significant degradation due to hydrolysis with Emcompress in powder mixes and direct compression tablets. The severity of this interaction was substantially reduced for aspirin in microencapsules

2) Aspirin does not show any compatibility problems when combined with acetaminophen. The combination is stable and does not show degradation in powder mixes as well as compressed tablets.

4 ) Aspirin does not interact with pseudoephedrine. Although the literature mentions the possibility of epimerization it was not observed in the laboratory experiments. The samples of aspirin - pseudoephedrine mixture were stable at room temperature as well as elevated temperature.

5 ) Acetaminophen reacts with antacids resulting in the adsorption of the drug over the antacid. The antacids tested were aluminum hydroxide, calcium carbonate and magnesium trisilicate. The severity of the interaction was found to be maximal in case of magnesium trisilicate and least in calcium carbonate. The response was similar in both powder mixes and compressed tablets. This interaction was eliminated completely when the drug was formulated in APAP Eurand microencapsules

6 ) There exist a characteristic interaction between acetaminophen and phenylephrine $\mathrm{HCL}$ \& diphenhydramine HCL. Acetaminophen formed a eutectic mixture with these drugs resulting in melting point depression. 
Microencapsules of acetaminophen gave physical protection against eutectic formation for both the drugs tested.

7 ) Pseudoephedrine does not show any interaction with acetaminophen and the mixture of these were found stable at room temperature as well as accelerated conditions. Microencapsulated acetaminophen gave similar results.

8 ) The statistical evaluation shows that there is a significant difference between the data sets obtained by the microencapsulated and non microencapsulated systems. 


\section{REFERENCES}

1 ) Botha, S., A., D. S. C. screening for drug - drug and drug - excipient interactions in polypharmaceuticals intended for alleviation of the symptoms of cold and flu., Drug Development \& Industrial Pharmacy 12 ( 6 ), 811 - 826, (1986)

2 ) Rippie, E., G., thru Remington's Pharmaceutical Sciences, 16 Th. edition, 1535 - 1576, ( 1980$)$.

3 ) Monkhouse, D., G., Solid state reactions - Theoretical and experimental aspects, Drug Development \& industrial Pharmacy, 10 ( 8 \& 9 ), 1175 - 1276, (1984).

4 ) Luzzi, L., A., Microencapsulation, Journal of Pharmaceutical Sciences, 59, (10), 1367 - 1369, (1970).

5 ) Rosemand, T., S., mandorf, Z., M., Controlled release delivery systems. Marcel Dekker Inc., New York, 177 - 181, ( 1983 )

6 ) Bakan, J., A., Anderson, J., L., in The Theory and Practice of Industrial Pharmacy Lackman, L., Libermann, H., Kanig, J., editors, 2 nd. edition, Lea and Febiger, Philadelphia, 420 - 424, ( 1976 ).

7 ) madan, P., L.,Pharmaceutical Technology, Dec. ( 1977 )

8 ) Shun, Por, Li, Recent advances in microencapsulation technology and equipment, Drug Development \& Industrial Pharmacy, 14 ( 2 \& 3 ), 353 - 376, (1988). 
9 ) Handbook of Non Prescription Drugs, American Pharmaceutical Association, 9 th edition, 1985.

10 ) Patel, N., K., et. al., The effect of selected direct compression excipients on the stability of aspirin as a model hydrolysable drug, Drug Development \& Industrial Pharmacy, 14 ( 1 ), 77 - 98, ( 1988 ).

11 ) Neelson, F., Manufacturing Chemistry, 38, 41 - 45, ( 1982 )

12 ) The condensed Chemical Dictionary, 4 Th. edition, Reinhold, New York, 1980.

13 ) Waltersson, et. al. Factorial design in preformulation studies I and II, Acta. Pharm. Suec. 23, $139-150$, ( 1986 ).

14 ) Handbook of Pharmaceutical Excipients.

15 ) Viviane, F., N., \& Grostic, M., F., In vito adsorption of some antirheumatics on antacids,Pharmazie_ 31, 461 - 465, ( 1976 ). 


\section{APPENDIX A}

Appendix A contains various calibration curves of microencapsulated and non microencapsulated drugs.( Fig 1 to Fig 6 ). The method used for plotting the calibration curves involved UV spectrophotometric determinations at various concentrations. The absorbance values were determined at various concentrations and plotted as ordinates. 
FIGURE 1 : Calibration curve of non - microencapsulated aspirin

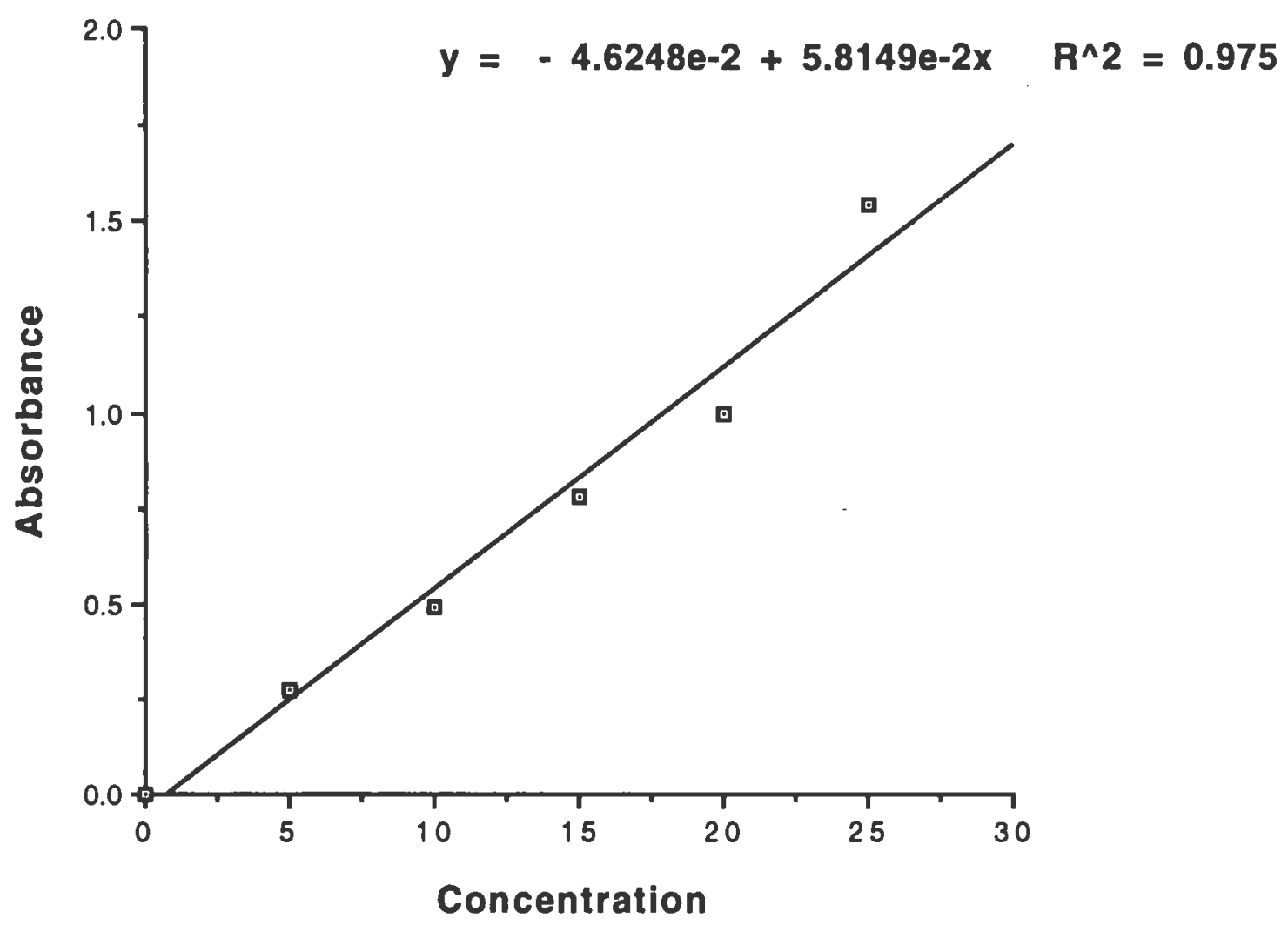


FIGURE 2 : Calibration curve of microencapsulated aspirin.

$$
y=5.9357 e-2+4.4087 e-2 x \quad R^{\wedge} 2=0.991
$$

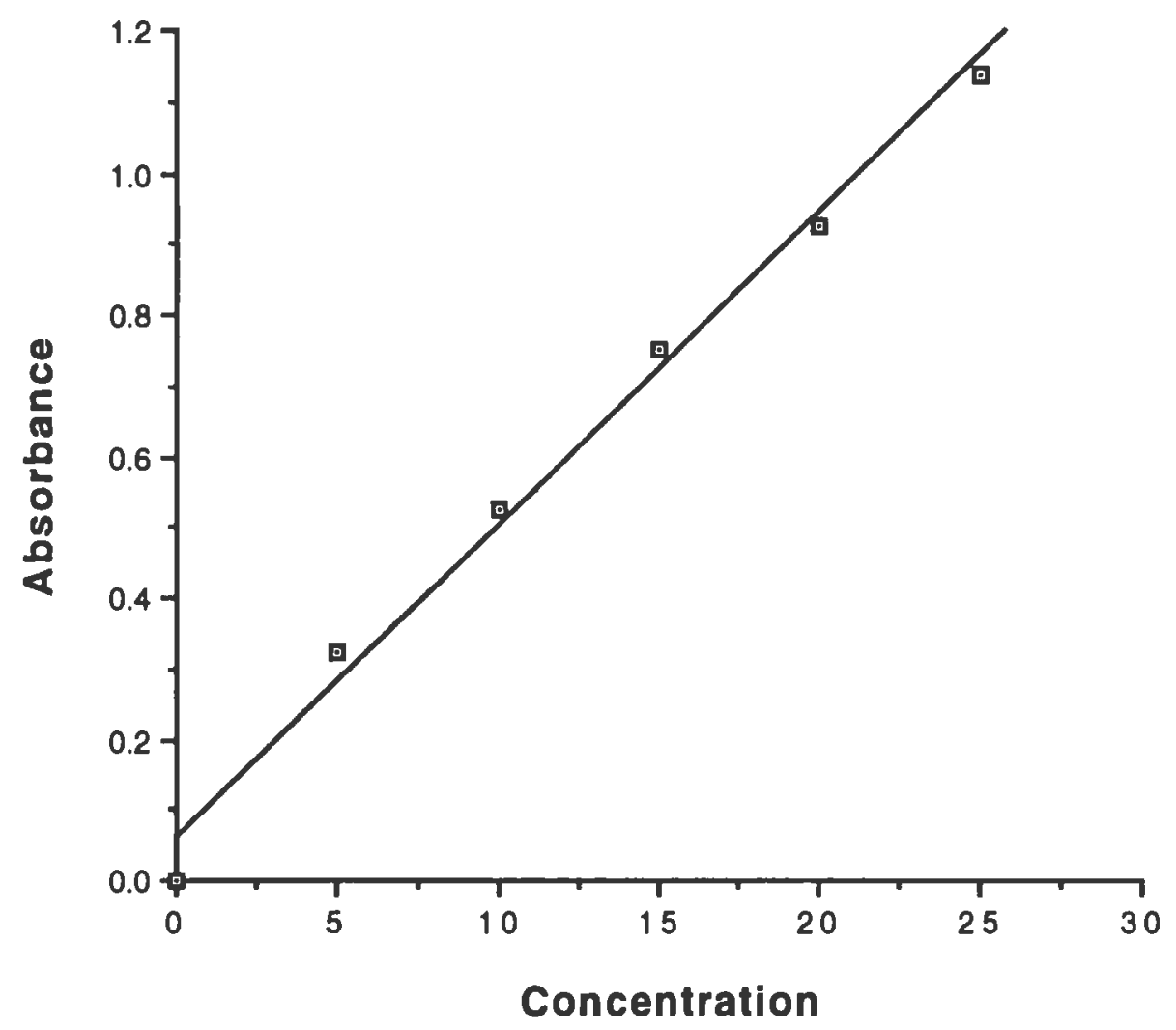


Figure 3 : Calibration curve of non microencapsulated acetaminophen.

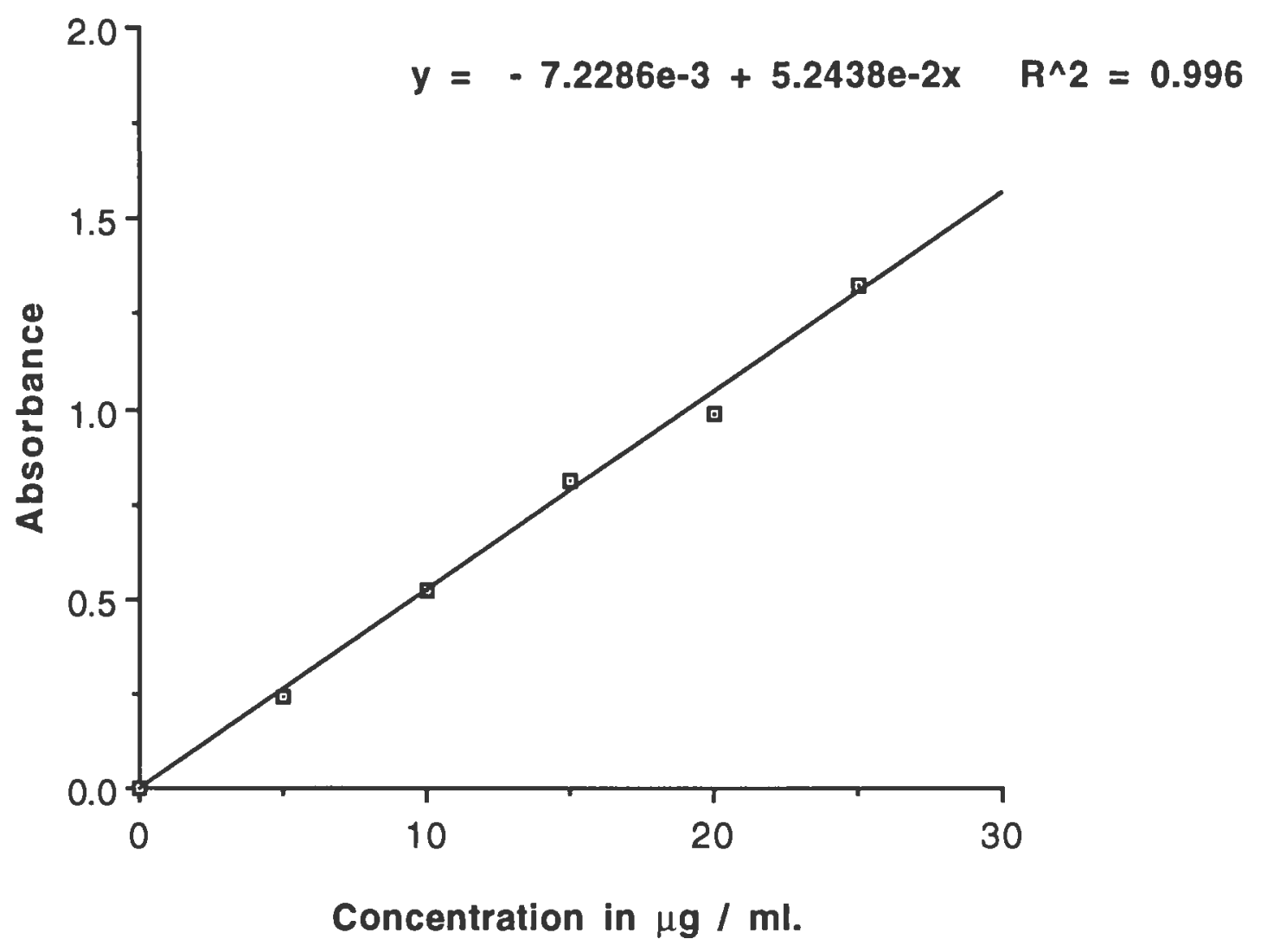


Figure 4 : Calibration curve of microencapsulated acetaminophen

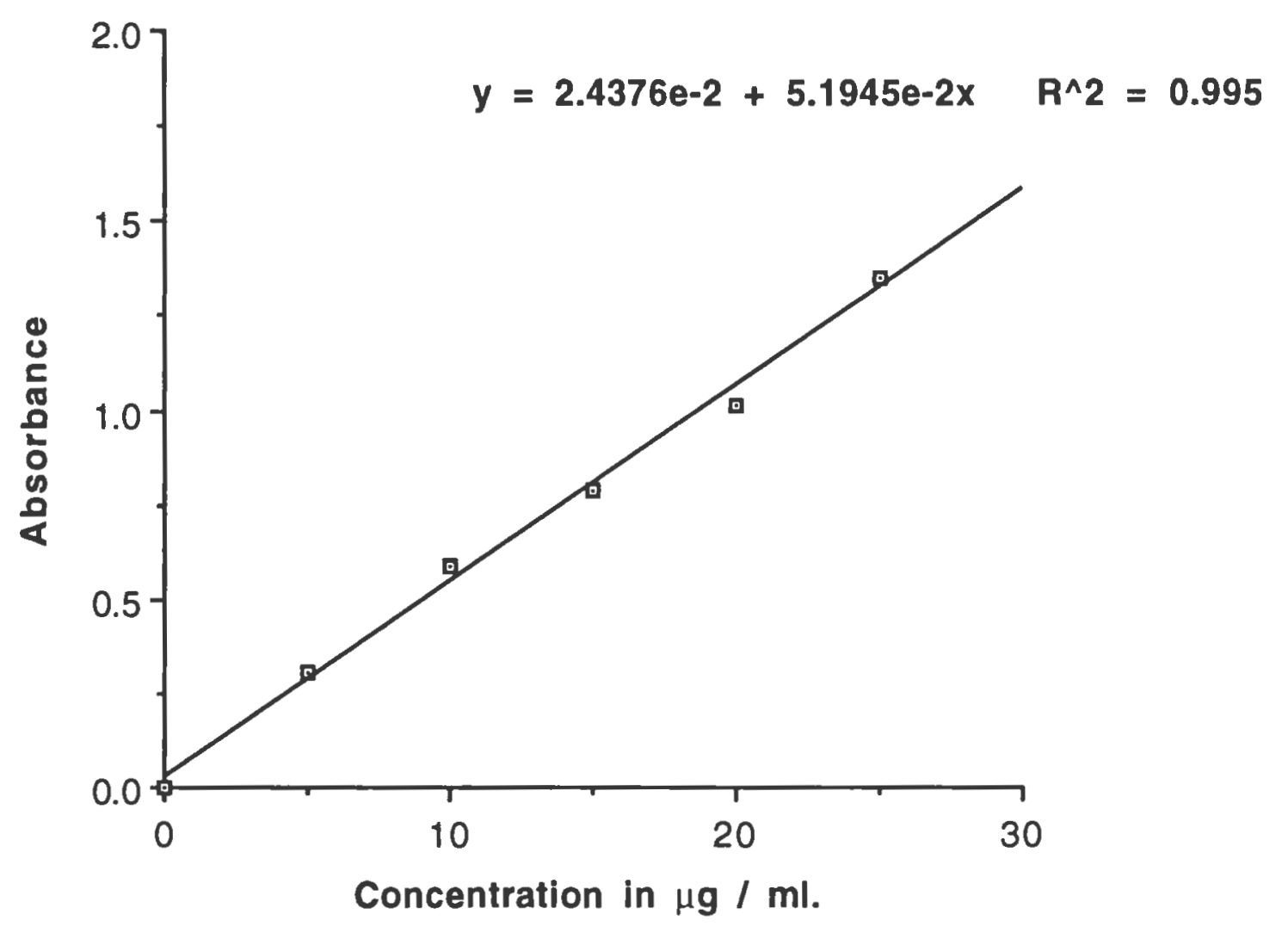


Figure 5 : Calibration curve of non microencapsulated pseudoephedrine hydrochloride.

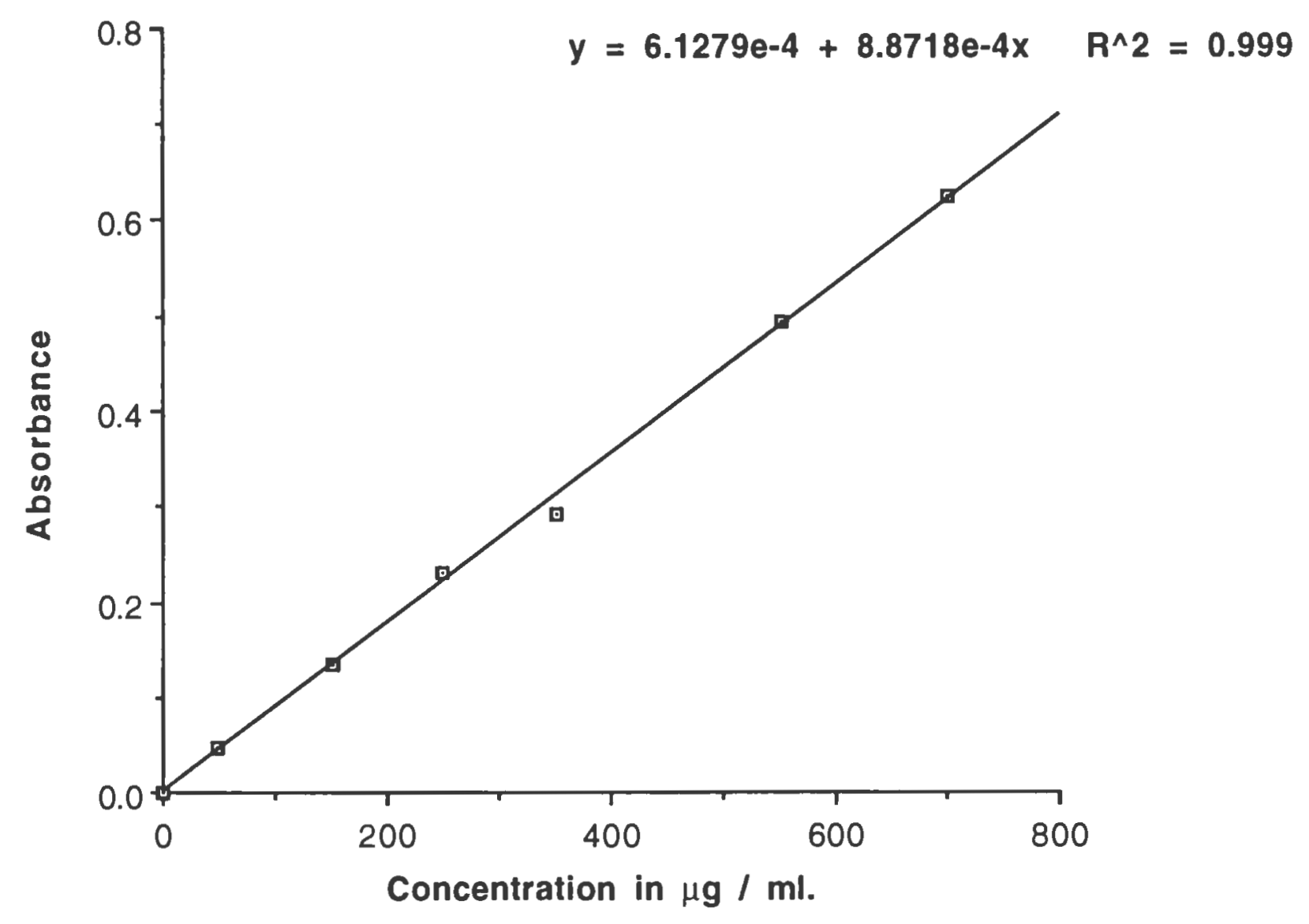


Figure 6 : Calibration curve of microencapsulated pseudoephedrine hydrochloride

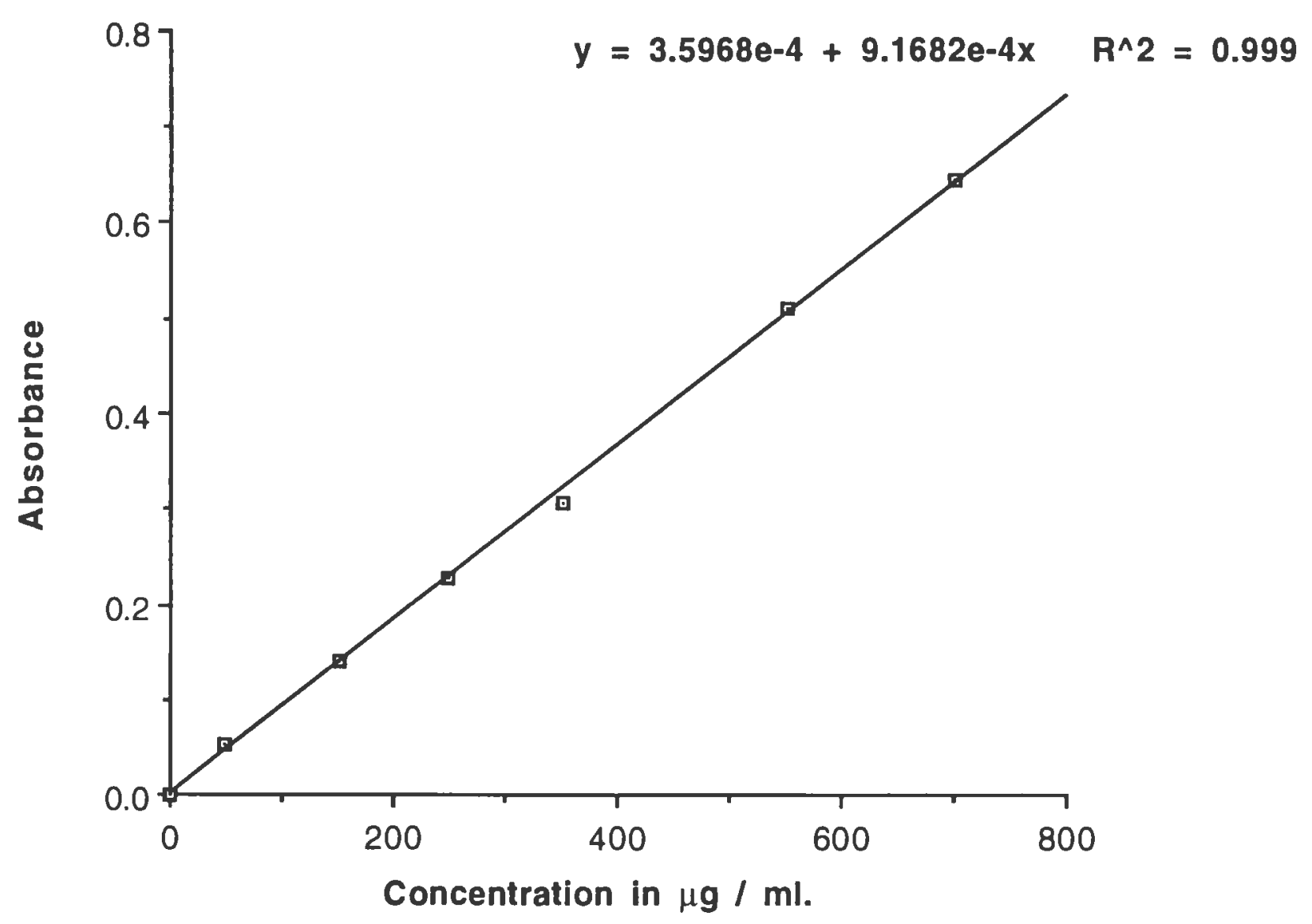




\section{APPENDIX B}

Appendix B ( Fig 7 to Fig 9 ) contains Scanning electron micrographs of aspirin, acetaminophen and pseudoephedrine hydrochloride at higher magnifications ( 200 and 3000 ) times. The procedure for obtaining these SEM is same as the one discussed under materials and methods. 
FIGURE 7 : Scanning electron micrographs ( magnified 200 and 3000 times ) of aspirin microencapsules
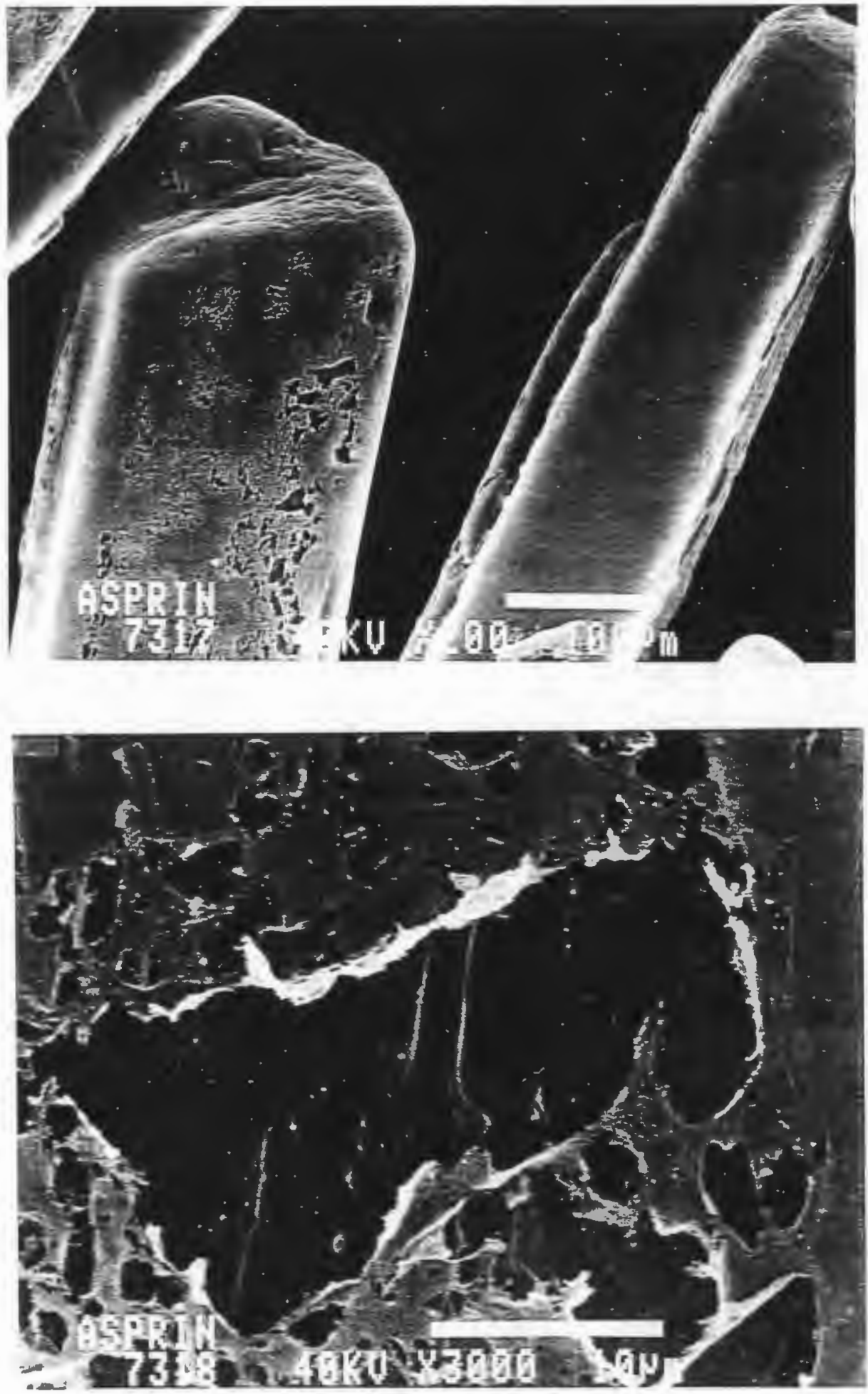
FIGURE : 8 Scanning electron micrographs of acetaminophen ( magnified 200 and 3000 times ) microencapsules.
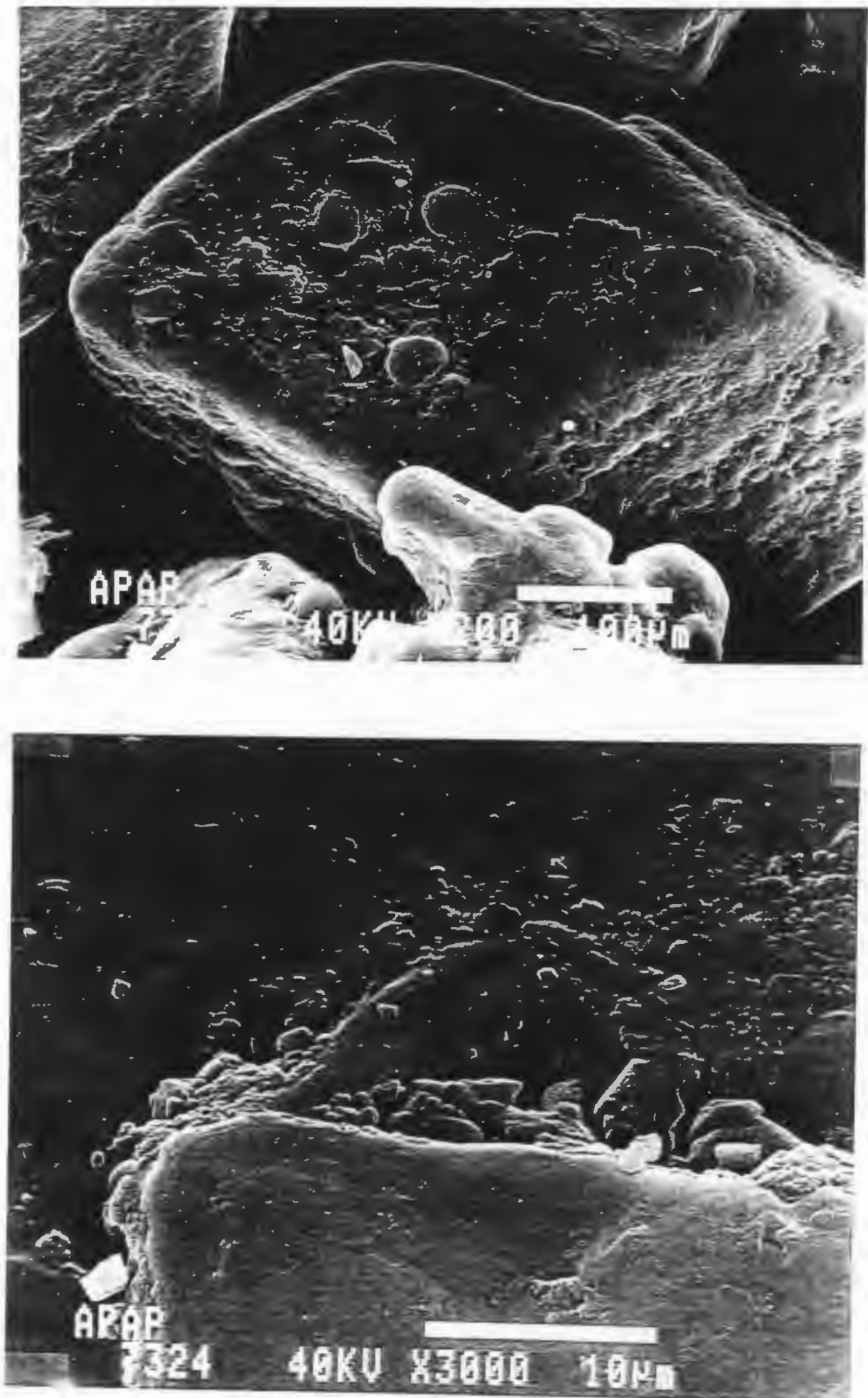
FIGURE 9 : Scanning electron micrographs of pseudoephedrine hydro chloride (magnified 200 and 3000 times ) microencapsules
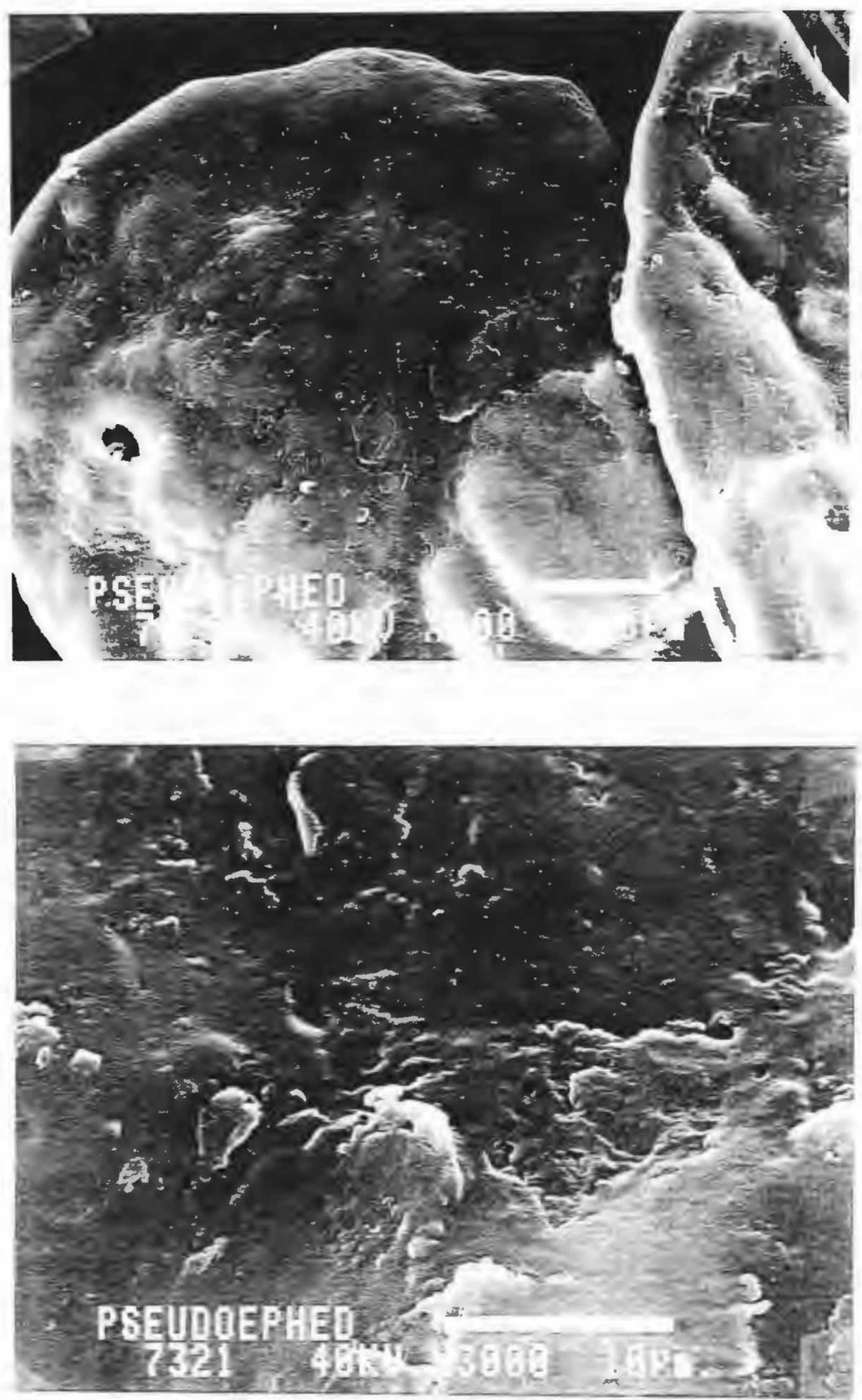


\section{APPENDIXC}

Appendix C contains

1 ) Dissolution data of acetaminophen with various antacids (Tables 1 to 3 ) in tablets.

2 ) UV analysis for the validation of the interaction between aspirin and Emcompress, for the determination of salicylic acid content. (Tables 4 to 8 )

3) Calibration curve data for the figures in appendix A. ( Tables 9 to 14 ). 
TABLE 1 : Dissoultion data of acetaminophen and aluminum hydroxide tablets

\begin{tabular}{|l|l|l|l|l|}
\hline Time in mins. & $\begin{array}{l}\text { unencapsulated } \\
\text { acetaminophen }\end{array}$ & $\begin{array}{l}\text { unencapsulated } \\
\text { acetaminophen }\end{array}$ & $\begin{array}{l}\text { Encapsulated } \\
\text { acetaminophen }\end{array}$ & $\begin{array}{l}\text { Encapsulated } \\
\text { acetaminophen }\end{array}$ \\
\hline & $\begin{array}{l}\text { Samples at } \\
\text { room temp. }\end{array}$ & $\begin{array}{l}\text { Samples at } \\
\text { elevated temp. }\end{array}$ & $\begin{array}{l}\text { Samples at } \\
\text { room temp. }\end{array}$ & $\begin{array}{l}\text { samples at } \\
\text { elevated temp. }\end{array}$ \\
\hline 5 & $9.30 \%$ & $9.83 \%$ & $10.53 \%$ & $10.36 \%$ \\
\hline 10 & $33.87 \%$ & $36.42 \%$ & $34.30 \%$ & $35.37 \%$ \\
\hline 15 & $45.86 \%$ & $47.96 \%$ & $48.22 \%$ & $49.96 \%$ \\
\hline 20 & $66.28 \%$ & $68.68 \%$ & $67.80 \%$ & $68.31 \%$ \\
\hline 25 & $68.37 \%$ & $70.57 \%$ & $75.90 \%$ & $78.15 \%$ \\
\hline 30 & $73.42 \%$ & $80.25 \%$ & $88.14 \%$ & $90.60 \%$ \\
\hline 45 & $78.01 \%$ & $81.63 \%$ & $93.68 \%$ & $95.32 \%$ \\
\hline
\end{tabular}


TABLE 2 : Dissoultion data of acetaminophen and calcium carbonate tablets:

\begin{tabular}{|c|c|c|c|c|}
\hline Time in mins. & $\begin{array}{l}\text { Unencapsulated } \\
\text { acetaminophen }\end{array}$ & $\begin{array}{l}\text { Unencapsulated } \\
\text { acetaminophen }\end{array}$ & $\begin{array}{l}\text { Encapsulated } \\
\text { acetaminophen }\end{array}$ & $\begin{array}{l}\text { Encapsulated } \\
\text { acetaminophen }\end{array}$ \\
\hline & $\begin{array}{l}\text { samples at } \\
\text { room temp. }\end{array}$ & $\begin{array}{l}\text { Samples at } \\
\text { elevated temp. }\end{array}$ & $\begin{array}{l}\text { Samples at } \\
\text { room temp. }\end{array}$ & $\begin{array}{l}\text { Samples at } \\
\text { elevated temp. }\end{array}$ \\
\hline 5 & $9.47 \%$ & $10.36 \%$ & $10.30 \%$ & $9.84 \%$ \\
\hline 10 & $33.47 \%$ & $34.54 \%$ & $37.49 \%$ & $36.84 \%$ \\
\hline 15 & $45.69 \%$ & $46.87 \%$ & $51.55 \%$ & $51.76 \%$ \\
\hline 20 & $62.67 \%$ & $66.67 \%$ & $70.41 \%$ & $69.64 \%$ \\
\hline 25 & $69.13 \%$ & $77.69 \%$ & $79.95 \%$ & $80.63 \%$ \\
\hline 30 & $84.68 \%$ & $87.91 \%$ & $92.53 \%$ & $91.05 \%$ \\
\hline 45 & $89.26 \%$ & $90.26 \%$ & $94.25 \%$ & $96.73 \%$ \\
\hline
\end{tabular}


TABLE 3 : Dissolution data of acetaminophen and magnesium trisilicate tablets :

\begin{tabular}{|c|c|c|c|c|}
\hline Time in mins. & $\begin{array}{l}\text { Unencapsulated } \\
\text { acetaminophen }\end{array}$ & $\begin{array}{l}\text { Unencapsulated } \\
\text { acetaminophen }\end{array}$ & $\begin{array}{l}\text { Encapsulated } \\
\text { acetaminophen }\end{array}$ & $\begin{array}{l}\text { Encapsulated } \\
\text { acetaminophen }\end{array}$ \\
\hline & $\begin{array}{l}\text { Samples at } \\
\text { room temp. }\end{array}$ & $\begin{array}{l}\text { samples at } \\
\text { elevated temp. }\end{array}$ & $\begin{array}{l}\text { Samples at } \\
\text { room temp. }\end{array}$ & $\begin{array}{l}\text { Samples at } \\
\text { elevated temp. }\end{array}$ \\
\hline 5 & $8.91 \%$ & $9.66 \%$ & $10.44 \%$ & $10.63 \%$ \\
\hline 10 & $34.13 \%$ & $34.18 \%$ & $35.92 \%$ & $37.07 \%$ \\
\hline 15 & $47.00 \%$ & $47.86 \%$ & $50.94 \%$ & $51.54 \%$ \\
\hline 20 & $65.97 \%$ & $66.71 \%$ & $68.60 \%$ & $69.92 \%$ \\
\hline 25 & $70.29 \%$ & $70.78 \%$ & $78.71 \%$ & $80.18 \%$ \\
\hline 30 & $75.83 \%$ & $78.47 \%$ & $91.97 \%$ & $94.02 \%$ \\
\hline 45 & $81.84 \%$ & $83.28 \%$ & $94.21 \%$ & $94.95 \%$ \\
\hline
\end{tabular}


Calculations for the determination of salicylic acid formed in the samples of aspirin by the method of simultaneous equations

\section{Week 1}

A $258=0.1631=258$ a aspirin * $b^{*} c$ aspirin +258 a sal. acid * b ${ }^{*} c$ sal. acid

A $302=0.002334=302$ a aspirin * $b^{*} c$ aspirin +302 a sal acid * $b^{*} c$ sal. acid

putting the values for absorptivities as per Table 4 we get two simultaneous equations in two unknowns

$0.1631=0.00695 \mathrm{C} a+0.00157 \mathrm{Cs}$

$0.002334=0.00035 \mathrm{C} a+0.0276 \mathrm{C}_{s}$

Multiplying equation 2 by 19.85 we get

$0.0463=0.00695 C_{a}+0.05488 C_{s}$

Subtracting ( 1 ) from ( 3 ) we get

$0.11685=0.5470 C_{s}$

Therefore

$\underline{c_{s}} \equiv 0.2135 \mathrm{\mu g} / \mathrm{ml}$.

Putting this value in equation ( 3 ) we get

$0.0463=0.00695 C a+0.5488(0.2135)$ 
Therefore

$\mathrm{C} \mathrm{a}=0.1628 / 0.00695=23.426 \mu \mathrm{g} / \mathrm{ml}$.

Thus concentration of aspirin remaining after one week in the sample is $23.426 \mu \mathrm{g} / \mathrm{ml}$. and that of salicylic acid is $0.2135 \mu \mathrm{g} / \mathrm{ml}$. These were the concentrations when the initial sample concentration was $25 \mu \mathrm{g} / \mathrm{ml}$.

Similar calculations were done for samples stored upto 6 weeks at $45^{\circ} \mathrm{C}$ and the content of salicylic acid was determined. Similar calculations were done for the samples containing aspirin microencapsules. The results obtained are summarized in the Table 7 for the samples containing non microencapsulated and in the Table 8 for the samples containing aspirin microencapsules. 
TABLE 4 : Molar absorptivities of aspirin and salicylic acid

\begin{tabular}{|l|l|l|}
\hline Compound & $302 \mathrm{~nm}$. & $258 \mathrm{~nm}$. \\
\hline Aspirin & & \\
\hline & 0.02765 & 0.00157 \\
\hline Salicylic acid & & \\
\hline
\end{tabular}


TABLE 5 UV analysis of samples containing non - microencapsulated aspirin as an avarage of three measurements. (Powder mix ).

\begin{tabular}{|l|l|l|}
\hline Time interval & $258 \mathrm{~nm}$ & $302 \mathrm{~nm}$. \\
\hline Week 1 & & \\
\hline Week 2 & 0.1631 & 0.002334 \\
\hline Week 3 & 0.1536 & \\
\hline & & 0.0497 \\
\hline Week 4 & 0.1523 & 0.0509 \\
\hline & & \\
Week 5 & 0.1509 & 0.0516 \\
\hline & & \\
Week 6 & 0.1489 & 0.0529 \\
\hline
\end{tabular}


TABLE 6 UV analysis of samples containing microencapsulated aspirin as an avarage of three measurements (powder mix).

\begin{tabular}{|l|l|l|}
\hline & & \\
\hline Time interval & $258 \mathrm{~nm}$. & $302 \mathrm{~nm}$. \\
\hline Week 1 & 0.1721 & \\
\hline Week 2 & & 0.004218 \\
\hline Week 3 & 0.1695 & \\
\hline & & 0.0501 \\
\hline Week 4 & 0.1618 & \\
\hline Week 5 & 0.1602 & 0.0529 \\
\hline & & 0.0566 \\
\hline Week 6 & 0.1587 & \\
\hline
\end{tabular}


TABLE 7 : UV analysis of samples containing non - microencapsulated aspirin as an average of three measurements :

\begin{tabular}{|l|l|l|}
\hline Time interval & Aspirin $(\mu \mathrm{g} / \mathrm{ml})$. & Salicylic acid $(\mu \mathrm{g} / \mathrm{ml})$. \\
\hline Week 1 & 23.426 & \\
\hline Week 2 & 21.759 & 0.2135 \\
\hline Week 3 & & 1.5222 \\
\hline Week 4 & 21.55 & \\
\hline & & 1.567 \\
\hline Week 5 & 21.35 & \\
\hline & & 1.5988 \\
\hline Week 6 & 20.98 & 1.6476 \\
\hline
\end{tabular}


TABLE 8 : UV analysis of samples containing microencapsulated aspirin as an average of three measurements :

\begin{tabular}{|l|l|l|}
\hline Time interval & Aspirin $(\mu \mathrm{g} / \mathrm{ml})$. & Salicylic acid $(\mu \mathrm{g} / \mathrm{ml})$. \\
\hline Week 1 & 24.22 & \\
\hline Week 2 & 24.047 & 0.1610 \\
\hline & & 1.510 \\
\hline Week 3 & 22.913 & \\
\hline Week 4 & & 1.623 \\
\hline & 22.652 & \\
Week 5 & & 1.760 \\
\hline & 22.42 & 1.827 \\
\hline Week 6 & & 1.881 \\
\hline
\end{tabular}


TABLE 9 : Calibration curve data of non - microencapsulated aspirin

\begin{tabular}{|l|l|}
\hline Concentration in $\mu \mathrm{G} / \mathrm{ml}$. & Absorbance \\
\hline 0 & 0.000 \\
\hline 5 & 0.2713 \\
\hline 10 & 0.4917 \\
\hline 15 & 0.7810 \\
\hline & \\
\hline 20 & 0.9989 \\
\hline & \\
\hline
\end{tabular}


TABLE 10 : Calibration curve data of microencapsulated aspirin

\begin{tabular}{|l|l|}
\hline Concentration in $\mu \mathrm{G} . / \mathrm{ml}$. & Absorbance \\
\hline & \\
\hline & 0.00 \\
\hline & \\
10 & 0.3241 \\
\hline & \\
\hline & 0.5243 \\
\hline 20 & 0.7514 \\
\hline & \\
\hline 25 & 0.9270 \\
\hline
\end{tabular}


TABLE 11 : Calibration curve data of non - microencapsulated acetaminophen.

\begin{tabular}{|l|l|}
\hline Concentration in $\mu \mathrm{G} . / \mathrm{ml}$. & Absorbance \\
\hline 0 & 0 \\
\hline 5 & 0.2376 \\
\hline 10 & 0.5221 \\
\hline 15 & 0.8136 \\
\hline & \\
\hline 20 & 0.9915 \\
\hline & \\
\hline
\end{tabular}


TABLE 12 : Calibration curve data of microencapsulated acetaminophen.

\begin{tabular}{|l|l|}
\hline Concentration in $\mu \mathrm{G} . / \mathrm{ml}$. & Absorbance \\
\hline 0 & 0.00 \\
\hline 5 & 0.3052 \\
\hline 10 & 0.5825 \\
\hline 15 & 0.7901 \\
\hline & \\
\hline & 1.0116 \\
\hline 25 & \\
\hline
\end{tabular}


TABLE 13 : Calibration curve data of non - microencapsulated pseudoephedrine hydrochloride :

\begin{tabular}{|l|l|}
\hline Concentration in $\mu \mathrm{G} . / \mathrm{ml}$. & Absorbance \\
\hline 0 & 0 \\
\hline 50 & 0.048 \\
\hline 150 & 0.135 \\
\hline 250 & 0.230 \\
\hline 350 & 0.293 \\
\hline 550 & 0.493 \\
\hline 750 & 0.624 \\
\hline
\end{tabular}


TABLE 14 : Calibration curve data of microencapsulated pseudoephedrine hydrochloride

\begin{tabular}{|l|l|}
\hline Concentration in mcg. / ml. & Absorbance \\
\hline 0 & 0.00 \\
\hline 50 & 0.052 \\
\hline 150 & 0.141 \\
\hline & \\
\hline & 0.228 \\
\hline 350 & 0.306 \\
\hline 550 & \\
\hline & 0.510 \\
\hline 700 & \\
\hline
\end{tabular}




\section{APPENDIX D}

Appendix $D$ contains UV absorbance studies on the interaction between acetaminophen and pseudoephedrine hydrochloride.( Tables 15 to 18 ). 
2 ) Interaction of pseudoephedrine with acetaminophen :

The combination of pseudoephedrine and acetaminophen was found to be stable at room temperature as well as accelerated conditions. The monitoring was done by UV spectrophotometric analysis.

Procedure :

a) For powder mixes kept at room temperature and accelerated conditions :

1) Weighed $200 \mathrm{gm}$. of pseudoephedrine and mixed with $200 \mathrm{gm}$. of acetaminophen in a turbula mixture at 90 RPM. for 30 mins.

2 ) Portions of $200 \mathrm{mg}$. were taken in $10 \mathrm{ml}$. open vial. The content uniformity of the samples were checked. It was in accordance with USP standards.

3 ) The samples were withdrawn initially and then at the regular intervals and the contents were analyzed spectrophotometrically in $0.1 \mathrm{~N} \mathrm{HCL}$.

4 ) The procedure was repeated for microencapsulated pseudoephedrine.

b ) Compressed tablets at room temperature and accelerated conditions :

1 ) Granules were prepared by wet granulation method and were compressed on the carver press.

2 ) The tablets characteristics were checked for weight variation, content uniformity, hardness, thickness and friability.

3 ) The tablets were subjected to dissolution test in Vanderkamp 600 
dissolution testing apparatus in $900 \mathrm{ml}$. of $0.1 \mathrm{~N} \mathrm{HCL}$ at $100 \mathrm{RPM}$

4 ) The samples were removed after $5,10,15,20,25,30,45,60$, and 90 mins. and analyzed spectrophotometrically at $256 \mathrm{~nm}$.

5 ) The rate of the interaction was determined in terms of the amount of pseudoephedrine remaining with respect to time. 
TABLE 15 : UV absorbance data of pseudoephedrine hydrochloride and acetaminophen mixture in powder mixes at $45 \mathrm{C}$ and $60 \% \mathrm{R}$. $\mathrm{H}$.

\begin{tabular}{|l|l|l|l|l|l|l|}
\hline Conc. & week 1 & week 2 & week 3 & week 4 & week 5 & week 6 \\
\hline $50 \mu \mathrm{g} / \mathrm{ml}$ & 0.0467 & 0.0451 & 0.0450 & 0.0457 & 0.0455 & 0.0451 \\
\hline $150 \mu \mathrm{g} / \mathrm{ml}$ & 0.1329 & 0.1322 & 0.1311 & 0.1316 & 0.1310 & 0.1303 \\
\hline $250 \mu \mathrm{g} / \mathrm{ml}$ & 0.2421 & 0.2419 & 0.2409 & 0.2411 & 0.2409 & 0.2401 \\
\hline & & & & & & \\
$350 \mu \mathrm{g} / \mathrm{ml}$ & 0.2969 & 0.2886 & 0.2881 & 0.2879 & 0.2876 & 0.2871 \\
\hline & & & & & & \\
$550 \mu \mathrm{g} / \mathrm{ml}$ & 0.5022 & 0.4997 & 0.4989 & 0.4981 & 0.4985 & 0.4981 \\
\hline & & & & & & \\
$700 \mu \mathrm{g} / \mathrm{ml}$ & 0.7021 & 0.7011 & 0.6994 & 0.6990 & 0.6993 & 0.6995 \\
\hline
\end{tabular}


TABLE 16 : UV absorbance data of pseudoephedrine hydrochloride and acetaminophen mixture in powder mixes at room temperature :

\begin{tabular}{|l|l|l|l|l|l|l|}
\hline Conc & week 1 & week 2 & week 3 & week 4 & week 5 & week 6 \\
\hline $50 \mu \mathrm{g} / \mathrm{ml}$. & 0.048 & 0.048 & 0.047 & 0.046 & 0.041 & 0.041 \\
\hline $150 \mu \mathrm{g} / \mathrm{ml}$ & 0.135 & 0.133 & 0.133 & 0.131 & 0.131 & 0.130 \\
\hline & & & & & & \\
$250 \mu \mathrm{g} / \mathrm{ml}$ & 0.230 & 0.230 & 0.230 & 0.226 & 0.226 & 0.225 \\
\hline & & & & & & \\
$350 \mu \mathrm{g} / \mathrm{ml}$ & 0.293 & 0.291 & 0.291 & 0.288 & 0.289 & 0.289 \\
\hline & & & & & & \\
$550 \mu \mathrm{g} / \mathrm{ml}$ & 0.493 & 0.488 & 0.488 & 0.486 & 0.485 & 0.484 \\
\hline & & & & & & \\
$700 \mu \mathrm{g} / \mathrm{ml}$ & 0.634 & 0.622 & 0.622 & 0.619 & 0.617 & 0.609 \\
\hline
\end{tabular}


TABLE 17 : UV absorbance data of pseudoephedrine hydrochloride and acetaminophen mixture in compressed tablets at $45 \mathrm{C}$ and $60 \% \mathrm{R} . \mathrm{H}$.

\begin{tabular}{|l|l|l|l|l|l|l|}
\hline Conc. & week 1 & week 2 & week 3 & week 4 & week 5 & week 6 \\
\hline $50 \mu \mathrm{g} / \mathrm{ml}$. & 0.0358 & 0.0347 & 0.0342 & 0.0336 & 0.0328 & 0.0319 \\
\hline $150 \mu \mathrm{g} / \mathrm{ml}$ & 0.1227 & 0.1229 & 0.1220 & 0.1205 & 0.1211 & 0.1198 \\
\hline & & & & & & \\
$250 \mu \mathrm{g} / \mathrm{ml}$ & 0.2856 & 0.2855 & 0.2844 & 0.2736 & 0.2715 & 0.2629 \\
\hline & & & & & & \\
$350 \mu \mathrm{g} / \mathrm{ml}$ & 0.3319 & 0.3306 & 0.3258 & 0.3244 & 0.3221 & 0.3209 \\
\hline & & & & & & \\
$550 \mu \mathrm{g} / \mathrm{ml} 1$ & 0.5927 & 0.5919 & 0.5857 & 0.5749 & 0.5699 & 0.5633 \\
\hline & & & & & & \\
$700 \mu \mathrm{g} / \mathrm{ml} 1$ & 0.8088 & 0.8071 & 0.8027 & 0.8005 & 0.7986 & 0.7926 \\
\hline
\end{tabular}


TABLE 18 UV absorbance data of pseudoephedrine hydrochloride and acetaminophen mixture in compressed tablets at room temperature :

\begin{tabular}{|l|l|l|l|l|l|l|}
\hline Conc. & week 1 & week 2 & week 3 & week 4 & week 5 & week 6 \\
\hline $50 \mu \mathrm{g} / \mathrm{ml}$. & 0.0363 & 0.0352 & 0.0345 & 0.0341 & 0.0339 & 0.0328 \\
\hline $150 \mu \mathrm{g} / \mathrm{ml}$ & 0.1215 & 0.1207 & 0.1191 & 0.1136 & 0.1028 & 0.1019 \\
\hline & & & & & & \\
$250 \mu \mathrm{g} / \mathrm{ml}$ & 0.2581 & 0.2491 & 0.2386 & 0.2297 & 0.2163 & 0.2159 \\
\hline $350 \mu \mathrm{g} / \mathrm{ml}$ & 0.3266 & 0.3197 & 0.3171 & 0.3126 & 0.3121 & 0.3122 \\
\hline & & & & & & \\
$550 \mu \mathrm{g} / \mathrm{ml}$ & 0.5712 & 0.5692 & 0.5496 & 0.5478 & 0.5466 & 0.5468 \\
\hline & & & & & & \\
$700 \mu \mathrm{g} / \mathrm{ml}$ & 0.7889 & 0.7811 & 0.7791 & 0.7721 & 0.7714 & 0.7708 \\
\hline
\end{tabular}




\section{BIBLIOGRAPHY}

Arshady, Reza, Albumin microspheres and microcapsules : methodology of manufacturing techniques, Journal of Controlled Release, 14, $111-131$ (1990).

Arshady, Reza, Preparation of biodegradable microspheres and microcapsules : 2 Polyactides and related polyesters, Journal of Controlled Release, 14, $141-149$ ( 1990 ).

Artursson, P., Characterization of polyacrylstarch microparticles suitable as carriers of proteins and drugs, Journal of Pharmaceutical Science _73, 1507 1513, (1984).

Bakan, J., A., Powel, T., C., Stability of controlled release pharmaceutical microcapsules, Controlled drug delivery systems, $177-188$, ( 1982 ).

Baves, A., K. , Microencapsulation of soluble pharmaceuticals, Journal of Microencapsulation.3 (1), 33 - 37, ( 1986 ).

Benita, S., Pathak, Y., V., Barkai, A., Effect of drug loading extent on the invitro release kinetic behaviour of nifedipine from polyacrylate microspheres, Journal of Controlled release, 12, 213 - 222, ( 1990 ).

Bhargava, et. al., Immobilization of active urokinase on albumin microspheres: Use of a chemical dehydrant and process monitoring, Pharmaceutical Research, 9 ( 6 ), ( 1992 ). 
Colley, C., M., and Ryman, B., E., The use of liposomally entrapped enzyme in the treatment of artificial storage condition, Biochim. Biophys. Acta, 451, $417-425(1976)$.

Conrad, J., M., and Robinson, J., R., in Pharmaceutical dosage form : tablets, Laberman, H., A., and Lackman, L., A., eds. 3, Dekker, New York, 149 (1982)

Dalal, P., S., and Narurkar, M., M., In vito and in vivo evaluation of sustained release suspensions of ibuprofen, International Journal Of Pharmaceutics.73, $157-162,(1991)$.

Edman, P., Ekman, B., Sjoholm, I., Journal of Pharmaceutical Sciences, 72 , $658-665,(1986)$.

Ekman, B., Sjoholm, I., Improved stability of proteins immobilized in microparticles by modified emulsion polymerization technique, Journal of Pharmaceutical Sciences, 67, 693 - 695, ( 1985 ).

Finkelstein, M., and Weissman, G., The introduction of enzymes into cells by means of liposomes, Journal of lipid research, 19, 289 - 303. ( 1985 ).

Gregoriadis, G., Liposomes as drug carriers, Pharmacy International, 33 - 37 , (1983).

Ho - Leung Fung in Chemical kinetics and drug stability, Modern Pharmaceutics, 2 nd. edition, Marcel Dekker, 227 - 231 ( 1986 ).

Johnson, R., E., Stability of atriopeptin III in polymicrospheres, Journal of Controlled release $17,61-68,(1991)$. 
Kawashima, et. al., Uniform and improved bioavailability of newly developed rapid and suatained release suspensions of microspheres, International Journal of Pharmaceutics, 89, 9 - 17 (1993).

Khalil, et. al. , In vitro availability of some salicylates from their caffeine complexes, canadian Journal of Pharmaceutical Sciences, 10, ( 3 ), 83 - 88, (1975).

Kreuter, J., Evaluation of nanoparticles for drug delivery systems I: Preparation methodes, Acta Pharmaceutica Helvitica., 58, 196 - 209, (1983)

Kreuter, J., Evaluation of nanoparticles as drug delivery systems III, Materials, stability, toxicity, possibilities of targetting and use, Acta Pharmaceutica Helvitica. 58, $242-250,(1983)$.

Lee, K., C., Complexation of aspirin with caffeine, Australian iournal of Pharmaceutical Sciences , 8, $56-60,(1975)$.

Levy, M., C., and Andry, M., C., Microencapsules prepared by interfacial cross linking of starch derivatives, International Journal of Pharmaceutics , 62, 27-35, ( 1990$)$.

Marty, J., M., Nanoparticles - a new colloidal drug delivery system Acta Pharmaceutica Helvitica. 53, 17 - 23, ( 1980 ).

Morishita, et. al., Novel oral microspheres of insulin with protease inhibitor protecting from enzyme degradation, International Journal Of Pharmaceutics. 78, 1 - 7 ( 1992$)$. 
Nastume Hideshi, Preparation and evaluation of biodegradable albumin microspheres containing mitomycin C, International Journal of Pharmaceutics.58, $79-87$ ( 1990$)$.

Oppenheim, R., C., Solid colloidal drug delivery systems : Nanoparticles , International Journal Of Pharmaceutics, 8 , 217 234, ( 1981 ).

Rosenberg, M., Kopelman, I., J., and Talman, Y., Agriculture \& Food Chemistry, 38, $1288-1294,(1990)$.

Sveinsson, S., J., Naproxen microcapsules : preparation and in vitro characterization, International Journal Of Pharmaceutics, 82, $129-133$, (1992).

Tirkkonen Sirpa, Paronen Petleri, Enhancement of drug release from ethyl cellulose microcapsules using sodium chloride in the wall, International Journal of Pharmaceutics, 88, $39-51$, ( 1992 ).

Vudathala, G., K., Microencapsulation of solid dispersions, Pharmaceutical Research, $9(6),(1992) \cdot 115-126$

Wilder, K., J., and Sengui, A., E., Magnetic microspheres : a vehicle for selective targetting of drugs, Pharmacotherapeutics, 20, 377 - 397. (1983). 